This is the accepted version of the following article: Tian, F. et al. Coupling of ecosystem-scale plant water storage and leaf phenology observed by satellite in Nature ecology and evolution (Ed. Nature publishing), vol. 2, issue 9 (Sep. 2018), p. 1428-1435

Which has been published in final form at DOI 10.1038/s41559-0180630-3

(C) 2018. This version is made available under a "All rights reserved" license 


\section{Coupling of ecosystem-scale plant water storage and foliar phenology observed by satellite}

2 Feng Tian ${ }^{1,2 *}$, Jean-Pierre Wigneron ${ }^{3 *}$, Philippe Ciais ${ }^{4}$, Jérôme Chave ${ }^{5}$, Jérôme Ogée ${ }^{3}$, Josep Peñuelas ${ }^{6,7}$, Anders

3 Ræbild ${ }^{2}$, Jean-Christophe Domec ${ }^{8}$, Xiaoye Tong ${ }^{2}$, Martin Brandt ${ }^{2}$, Arnaud Mialon ${ }^{9}$, Nemesio Rodriguez-

4 Fernandez ${ }^{9}$, Torbern Tagesson ${ }^{1,2}$, Amen Al-Yaari ${ }^{3}$, Yann Kerr ${ }^{9}$, Chi Chen ${ }^{10}$, Ranga B. Myneni ${ }^{10}$, Wenmin

5 Zhang $^{2}$, Jonas Ardö ${ }^{1}$, Rasmus Fensholt ${ }^{2}$

$6 \quad{ }^{1}$ Department of Physical Geography and Ecosystem Science, Lund University, Lund, Sweden.

$7 \quad{ }^{2}$ Department of Geosciences and Natural Resource Management, University of Copenhagen, Copenhagen,

8 Denmark.

$9 \quad{ }^{3}$ INRA, UMR 1391 ISPA, Bordeaux, France.

$10{ }^{4}$ Laboratoire des Sciences du Climat et de l'Environnement, CEA/CNRS/UVSQ, Gif-sur-Yvette, France.

$11{ }^{5}$ UMR5174 Laboratoire Evolution et Diversité Biologique, Université Paul Sabatier, CNRS, Toulouse, France.

$12{ }^{6}$ CSIC, Global Ecology Unit CREAF-CSIC-UAB, Bellaterra, Spain.

$13 \quad{ }^{7}$ CREAF, Cerdanyola del Vallès, Spain.

$14{ }^{8}$ Bordeaux Sciences Agro, UMR 1391 INRA-ISPA, Gradignan, France.

$15{ }^{9}$ CESBIO, Université de Toulouse, CNES/CNRS/ IRD/UPS, Toulouse, France.

$16{ }^{10}$ Department of Earth and Environment, Boston University, Boston, USA. 


\section{Introductory paragraph}

18 Plant water storage is fundamental to the functioning of terrestrial ecosystems by participating in plant metabolism, 19 nutrient and carbohydrates transport, and maintenance of the plant hydraulic system's integrity. However, global 20 observations of the size and dynamics of the water pools stored in plant tissues do not exist. Here we reveal the

21 global patterns of seasonal variations in ecosystem-scale plant water storage and their relationship with foliar 22 phenology, based on the novel space-borne measurements of L-band vegetation optical depth (L-VOD). We find 23 that seasonal variation in plant water storage is highly synchronous with foliar phenology for the boreal and 24 temperate forests, but asynchronous with a time lag of up to 180 days for the tropical dry woodlands. Contrasting 25 patterns of the time lag between plant water storage and terrestrial groundwater storage anomaly are also presented 26 amongst these ecosystems. Comparison of the water-cycle components in seasonally-dry tropical woodlands 27 suggests a buffering effect of plant water storage on the seasonal dynamics of water supply and demand. Our

28 results offer new insights into ecosystem-scale plant water relations globally and provide a basis for an improved 29 parameterization of process-based eco-hydrological and earth system modelling. 
and nutrient/sugar transport) and sustains the integrity of the plant hydraulic system through buffering the imbalance between transpirational water loss and root-soil water uptake $e^{1,2}$. Water movement in plants is a passive process, following a gradient of water potential (from higher to lower) generated by transpirational demand (regulated by stomata) $)^{3}$ and different solute concentrations between cells (osmosis) ${ }^{4}$. In response to changes in environmental conditions and metabolic activities, plant water storage varies from diurnal to seasonal timescales as a function of plant structure and hydraulic strategies ${ }^{5-7}$. Studies on the dynamics of plant water storage typically use measurements of sap flow hysteresis and leaf water potential on individual trees over relatively limited periods $^{7-10}$. Scaling up tree-level data to the ecosystem scale is challenging due to the high spatial heterogeneity of plant composition and soil properties, thus precluding large-scale (continental or global) estimates of the dynamics of plant water storage.

Satellite passive microwave radiometers sense the natural earth surface thermal emission at wavelengths of 0.1-30 $\mathrm{cm}$ from both the soil and vegetation layers, quantified as brightness temperature. The vegetation layer is semitransparent, attenuating the microwave radiations passing through and creating a vegetation optical depth (VOD) proportionally linked to the vegetation water content $\left(\mathrm{kg} / \mathrm{m}^{-2}\right)^{11,12}$. The higher the microwave frequency, the stronger the vegetation attenuation effect. The low frequency L-band (1.4 GHz) VOD (L-VOD) can detect changes in plant water storage even for dense forest canopies ${ }^{13-15}$, where the woody tissues of stems and branches hold the majority of the plant water ${ }^{16}$. This detection was not possible from VOD products at higher frequencies $(>6 \mathrm{GHz})$, because their signals were dominated by the water status of canopy leaves ${ }^{13,14,17-19}$. Satellite-based VOD retrievals from X-band (10.7 GHz) observations over day-time and night-time have recently been used to map ecosystemscale anisohydricity, an indicator of stomatal and xylem regulation ${ }^{20,21}$. Since 2010, the first satellite-based L-band radiometer carried by the Soil Moisture and Ocean Salinity (SMOS) mission ${ }^{22}$ further enables global scale monitoring of the dynamics in forest plant capacitive water storage, which is another key functional trait in ecohydrological processes.

Here, we used the SMOS L-VOD product ${ }^{23,24}$ as a proxy for time and space variations in ecosystem-scale plant water storage and examined its seasonal dynamics globally over the period 2011-2016. Since leaf area scales the 
transpirational flux and photosynthetic productivity, we also examined the coupling between seasonal variations in L-VOD and foliar phenology (defined as the seasonality of satellite observed Leaf Area Index; LAI).

\section{Results and discussion}

60

61

62

63

64

65

66

67

68

69

\section{Seasonal amplitude of $L-V O D$}

We analysed the seasonal dynamics of ecosystem-scale plant water storage by concatenating six-year (2011-2016) SMOS L-VOD data into a mean yearly daily time series at a spatial resolution of $0.25^{\circ}$ (Methods; Extended Data Fig. 1). Large land regions had substantial data gaps due to the influence of radio frequency interference (RFI) on the SMOS signal ${ }^{25}$ (mainly in Asia; Extended Data Fig. 2), open water bodies, and lack of data retrievals from frozen soil in the northern latitudes during the cold season. We therefore restricted our analysis to pixels with continuous L-VOD data over 120 days and focused on four regions representing various biomes of contrasting ecosystem functioning: boreal, temperate, tropical dry, and tropical moist, based on a map of terrestrial ecoregions $^{26}$ (Extended Data Fig. 3). To ensure a high accuracy of the L-VOD seasonal patterns, we excluded areas with sparse vegetation cover where the tree cover fraction is below 5\% ${ }^{27}$ (Extended Data Fig. 4) and areas that were seasonally inundated ${ }^{28}$, i.e. $>5 \%$ area covered by flooding within an L-VOD pixel (Extended Data Fig. $5)$.

Globally, the annual maximum L-VOD was highly correlated with the distribution of tree cover fraction and tree

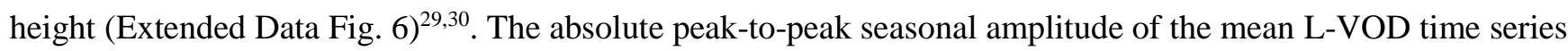
was similar (within 0.3 L-VOD units) amongst the four regions (Fig. 1a), even though plant productivity in these regions is limited by different climatic variables (e.g. temperature, water and radiation) and by different nutrient availability. The L-VOD seasonal amplitude relative to the annual maxima, however, differed significantly amongst regions (Fig. 1b), and were largest in the tropical dry region (>30\% on average) and smallest in the tropical moist region $(<10 \%$ on average), with temperate and boreal regions having intermediate values. 

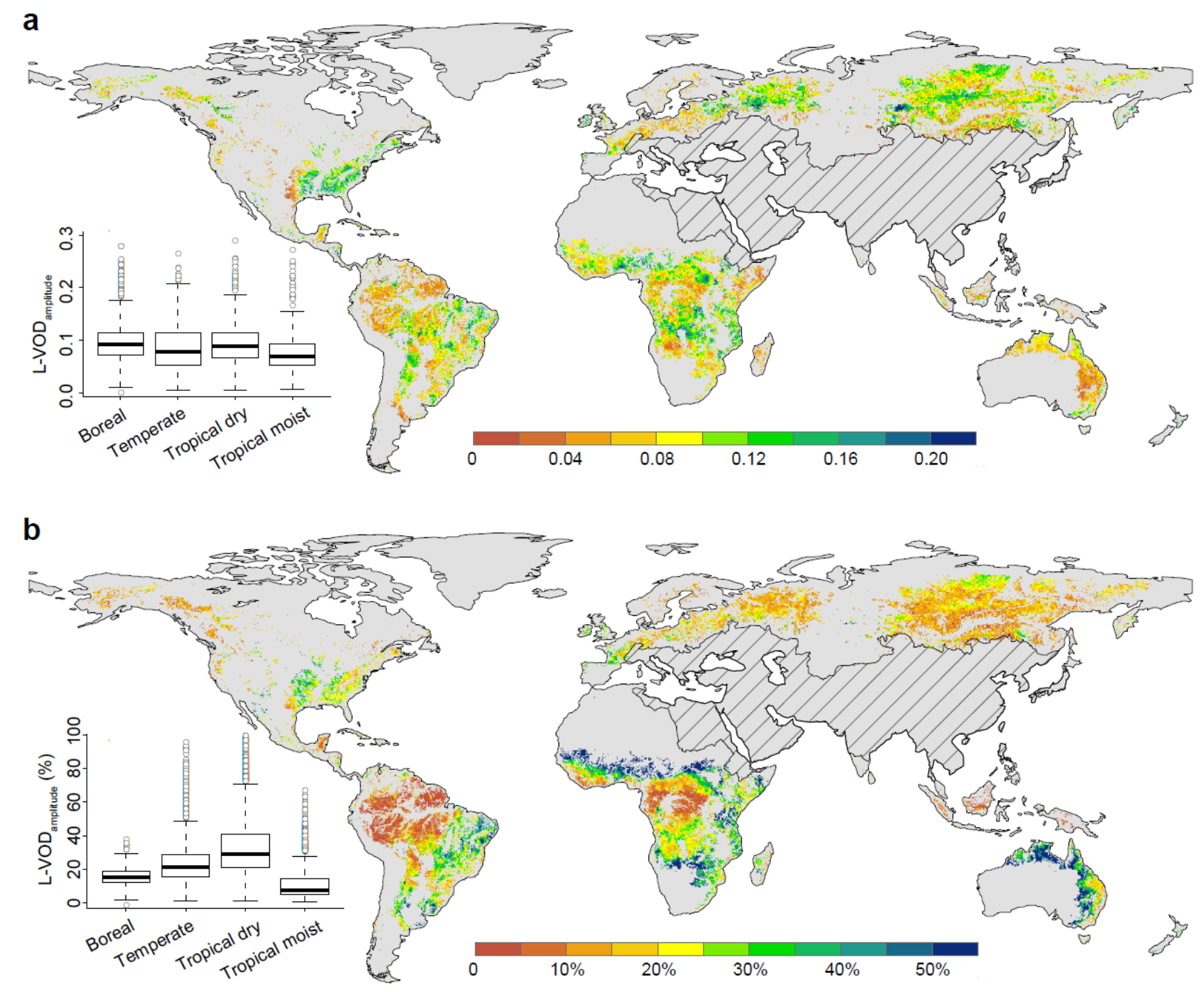

79

Figure 1: Seasonal amplitude of L-VOD. a, Absolute seasonal amplitude of L-VOD. b, Relative seasonal amplitude of LVOD normalized by the annual maxima. The inserted whisker plots are calculated for unfiltered pixels in four regions, i.e. boreal $(n=12880)$, temperate $(n=6775)$, tropical dry $(n=14152)$, and tropical moist $(n=7737)$. Areas with substantial data gaps, seasonal inundation, or eco-regions not considered in this study were filtered out and are shown in grey (see Extended Data Figures 2-5). Areas influenced by RFI are marked with hatching.

\section{Seasonal coupling of L-VOD and LAI}

Water stored in plant tissues and its seasonal dynamics differ substantially across vegetation lifeforms (e.g. woody vs. herbaceous plants). Herbaceous plants are usually annuals, so the seasonal amplitude of herbaceous water storage is determined primarily by the amount of foliage in the growing season. In contrast, trees store the majority of their water in woody tissues, with water-holding capacities varying amongst functioning tissues ${ }^{16,31}$. Also, 
determining the dynamics of water storage is more complex for woody than herbaceous plants, because trees may access deep soil water and have more sophisticated hydraulic strategies ${ }^{32-34}$. We examined the spatial relationships between the absolute seasonal amplitudes of L-VOD and LAI in each of the four regions. As expected, linear correlations between the two signals were higher in areas with limited tree cover $(5-10 \%)(R \approx 0.56, P<0.05$; Fig. $2)$, except in the boreal region $(R=0.24, P<0.05)$ where data gaps in winter may cause a partial loss of information in the transitional period between winter and spring/fall. The seasonal amplitudes of L-VOD, however, were positively correlated with LAI across space for areas with high tree cover $(>60 \%)$ in the boreal $(R=0.35, P<0.05)$ and temperate $(R=0.32, P<0.05)$ regions, but the relationship was much lower in the tropical moist $(R=0.09, P$ $<0.05)$ region and not significant $(R=-0.02, P>0.05)$ in the tropical dry region. These findings suggest a lower influence of foliar fluctuations on the seasonal amplitude of plant water storage in tropical than boreal or temperate forests.

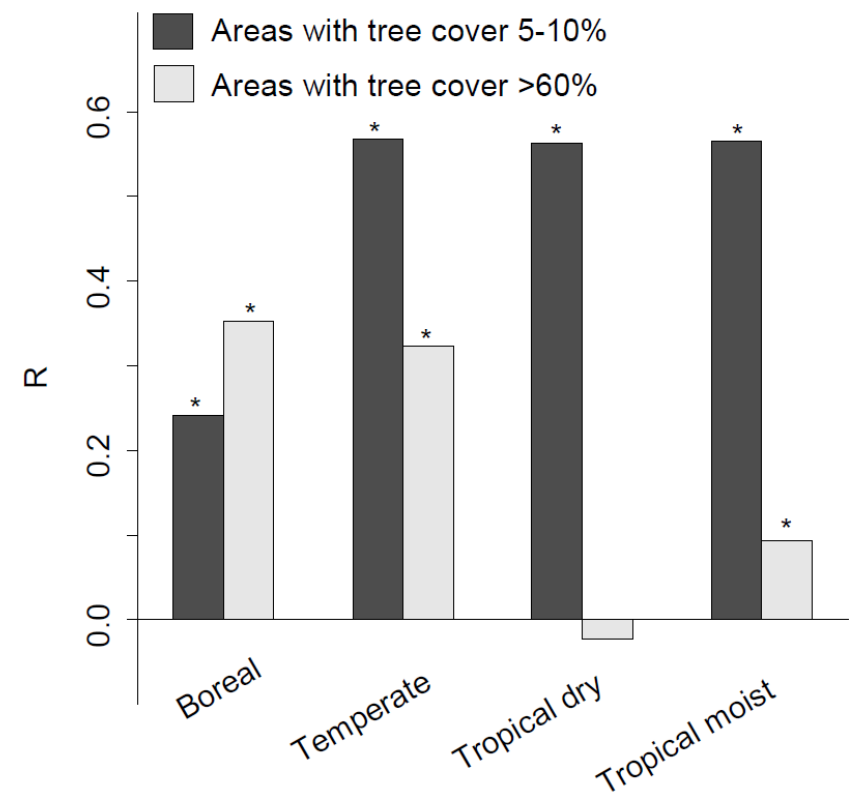

Figure 2: Relationship between seasonal amplitude of L-VOD and LAI. The Pearson correlation coefficients $(R)$ for areas with tree covers of 5-10\% and $>60 \%$ within the four regions: boreal $(n=699$ and 4193 , respectively), temperate $(n=1010$ and 1 236, respectively), tropical dry ( $n=1804$ and 1704, respectively), and tropical moist ( $n=237$ and 5 493, respectively). Significant correlations $(P<0.05)$ are labelled with asterisks. The scatterplots for each comparison are shown in Extended Data Fig. 7. 
We then examined the seasonal synchronicity of plant water storage and foliar phenology by calculating the time lag that characterizes the maximum Spearman rank correlation coefficient between L-VOD and LAI time series (for pixels with a clear seasonality in both indices; see Methods). The seasonal variations in L-VOD were highly synchronous with LAI in boreal and temperate regions $(R>0.9, P<0.05)$, with time lags ranging from -30 to +60 days (Fig. 3a; positive values represent L-VOD peaks succeeding LAI). In contrast, the relationship was clearly asynchronous in tropical woodlands (e.g. the woodlands around rainforests in the Congo basin), with time lags up to 180 days (Fig. 3a). This time lag was found to follow a gradient in L-VOD and tree cover in two African savannah and woodland regions (regions $\mathrm{i}$ and ii in Fig. 3a, b), but not in two other contrasted regions with wet summer in southeastern USA (region iii in Fig. 3a, b) and dry summer in central Siberia (iv in Fig. 3a, b), respectively. This suggests different strategies of the coupling between plant water storage and leaf phenology of certain tree species in the dry tropical woodlands as compared to temperate and boreal forests.

118 The average seasonality of L-VOD and LAI are shown in Fig. 3c for pixels with equivalent tree cover fractions (60-65\%) from each selected region. The long L-VOD/LAI time lags in tropical woodlands caused an almost reversed seasonal pattern between the two signals (Fig. 3c-i, -ii). We further included the seasonality of a high-

121 frequency X-band VOD $(\mathrm{X}-\mathrm{VOD})^{35}$, which is more related to the water content of the upper canopy since X-band 122 microwaves penetrate less than L-band microwaves. The seasonal curves of X-VOD were between L-VOD and 123 LAI (Fig. 3c), indicating a high consistency amongst the independent satellite observations. Moreover, we 124 performed a series of sensitivity analyses on the algorithm used to retrieve L-VOD to verify the robustness of the 125 observed seasonal patterns in the tropical dry region (Fig. 3a-i; see Methods and Extended Data Figs. 8-10). 

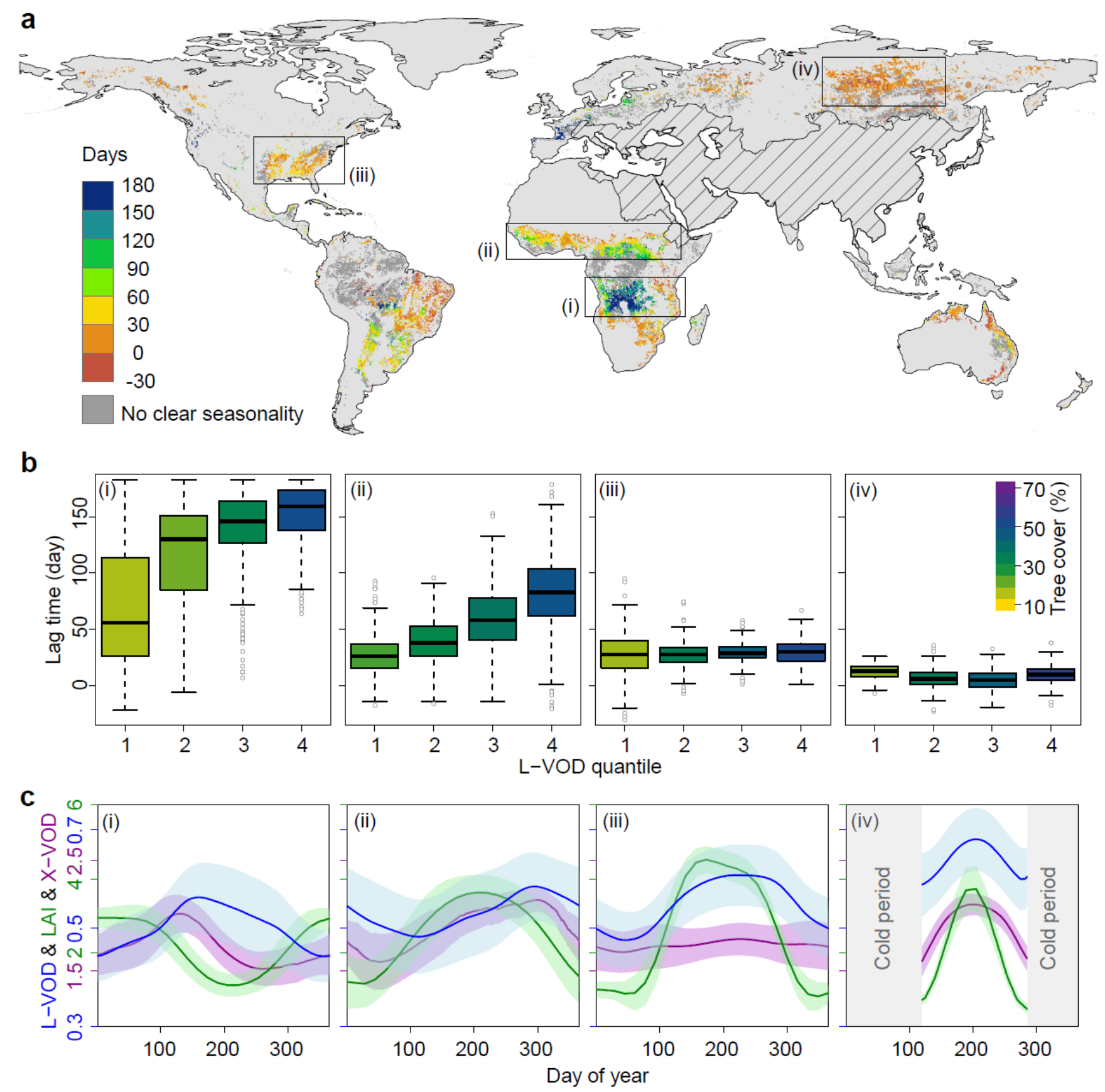

126

127 Figure 3: Temporal coupling between L-VOD and LAI seasonality. a, Lag time for L-VOD to obtain the highest correlation with LAI for pixels with a clear seasonality. Areas influenced by RFI are marked with hatching. b, Spatial relationships between L-VOD/LAI lag time, annual maximum L-VOD, and tree cover fraction for the four selected areas 130 indicated in a by black rectangles. c, Seasonal curves of mean L-VOD, LAI, and X-VOD for the pixels with a tree cover of $60-65 \%$ for the four selected areas $(\mathrm{n}=152,79,124$, and 212 , respectively). The shaded curves represent the standard deviations. No VOD values were retrieved during winter periods with frozen soils. 
Plants regulate water exchange between sub-soil layers and the atmosphere through soil water uptake and transpiration. We evaluated the role of plant water storage on the seasonal water balance at ecosystem scale by analysing the development of various components of the water cycle, including plant water storage (L-VOD), terrestrial groundwater storage anomaly (TWS), surface soil moisture (SM), rainfall, and estimates of transpiration.

138 The TWS integrates the ground water from the soil surface to deep ground ${ }^{36}$. Seasonal variations in TWS indicate 139 the net balance between soil water replenishment (e.g., by rainfall) and consumption (e.g., by 140 evapotranspiration $)^{37}$. We calculated the seasonal time lag between L-VOD and TWS as it was done for L-VOD 141 and LAI. Large time lags of about 120 and 90 days were obtained in the entire regions of southeastern US and 142 central Siberia, respectively (Fig. 4). By contrast, a time lag varying from 0 to around 90 days was found in the 143 central south African savannah/woodland region (the Miombo region), following the gradient of vegetation density 144 (L-VOD and tree cover; Fig. 4) thus suggesting the unique role of certain tree species in the eco-hydrological 145 processes as compare to the herbaceous vegetation. 


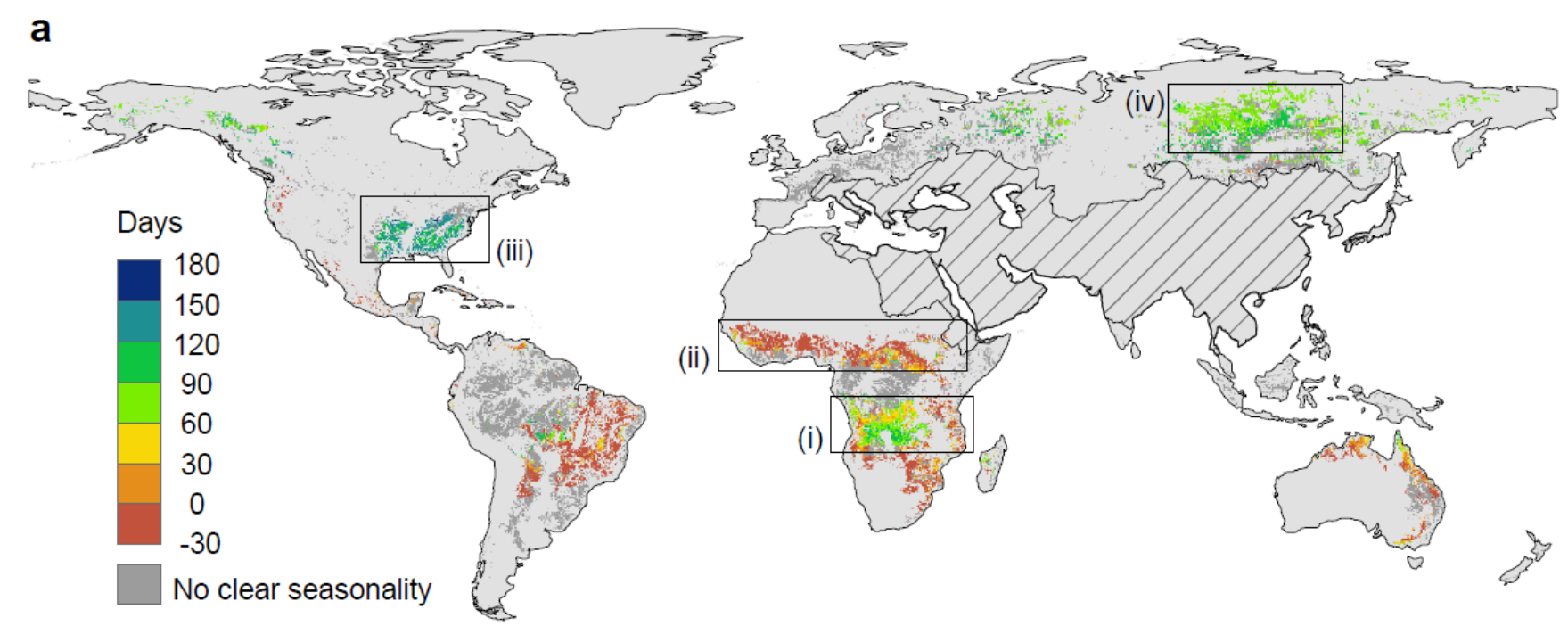

b
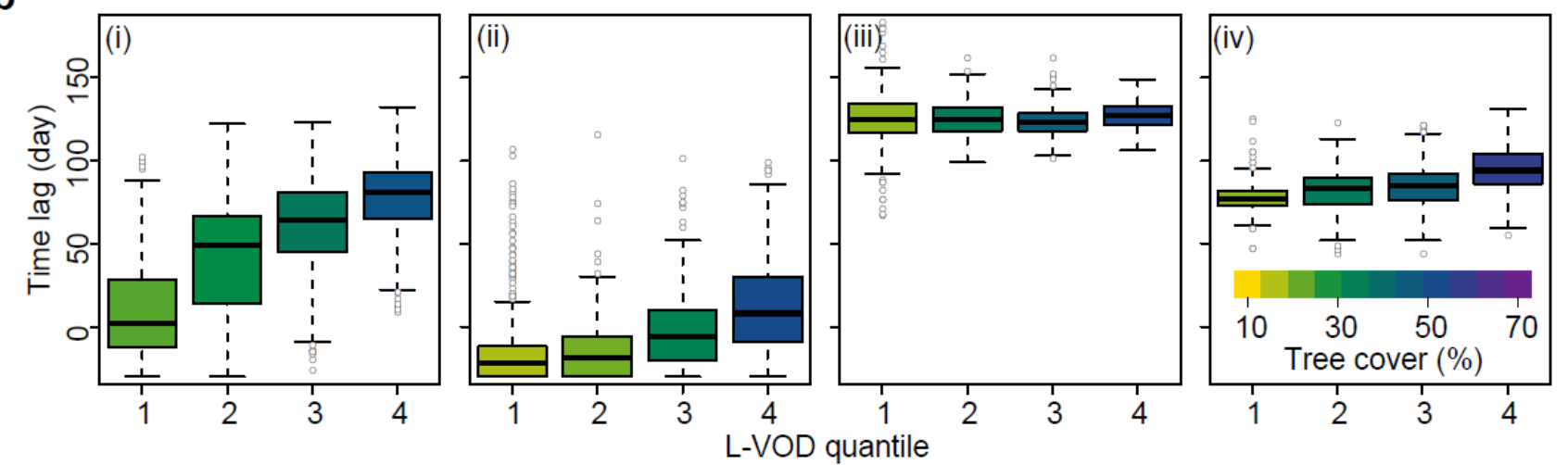

Figure 4: Temporal coupling between L-VOD and TWS seasonality. a, Lag time for L-VOD to obtain the highest correlation with TWS for pixels with a clear seasonality. Areas influenced by RFI are marked with hatching. b, Spatial relationships between L-VOD/TWS lag time, annual maximum L-VOD, and tree cover fraction for the four selected areas indicated by black rectangles.

To better illustrate the seasonal variation in relevant water cycle components, we studied two sites with a $1^{\circ} \times 1^{\circ}$ spatial extent (16 L-VOD pixels) in the period 2011-2012 (Fig. 5): one in the US temperate forests (region iii of Figs. 3-4, centred at $33.5^{\circ} \mathrm{N}, 85.5^{\circ} \mathrm{W}$ ) and one in the African Miombo woodlands (region i of Figs. 3-4, centred at $\left.11.5^{\circ} \mathrm{S}, 18.5^{\circ} \mathrm{E}\right)$. For the US temperate forests, rainfall and $\mathrm{SM}$ were relatively homogenous throughout the year, whereas TWS exhibited clear seasonal fluctuations. TWS reached the lowest level by the end of growing season, then increased and peaked around the start of growing season, followed by a continuous decrease during the growing season (Fig. 5a). Given the equalized water replenishment from rainfall over time, the seasonal 

stem water storage to buffer the xylem tension induced by transpiration ${ }^{38}$.
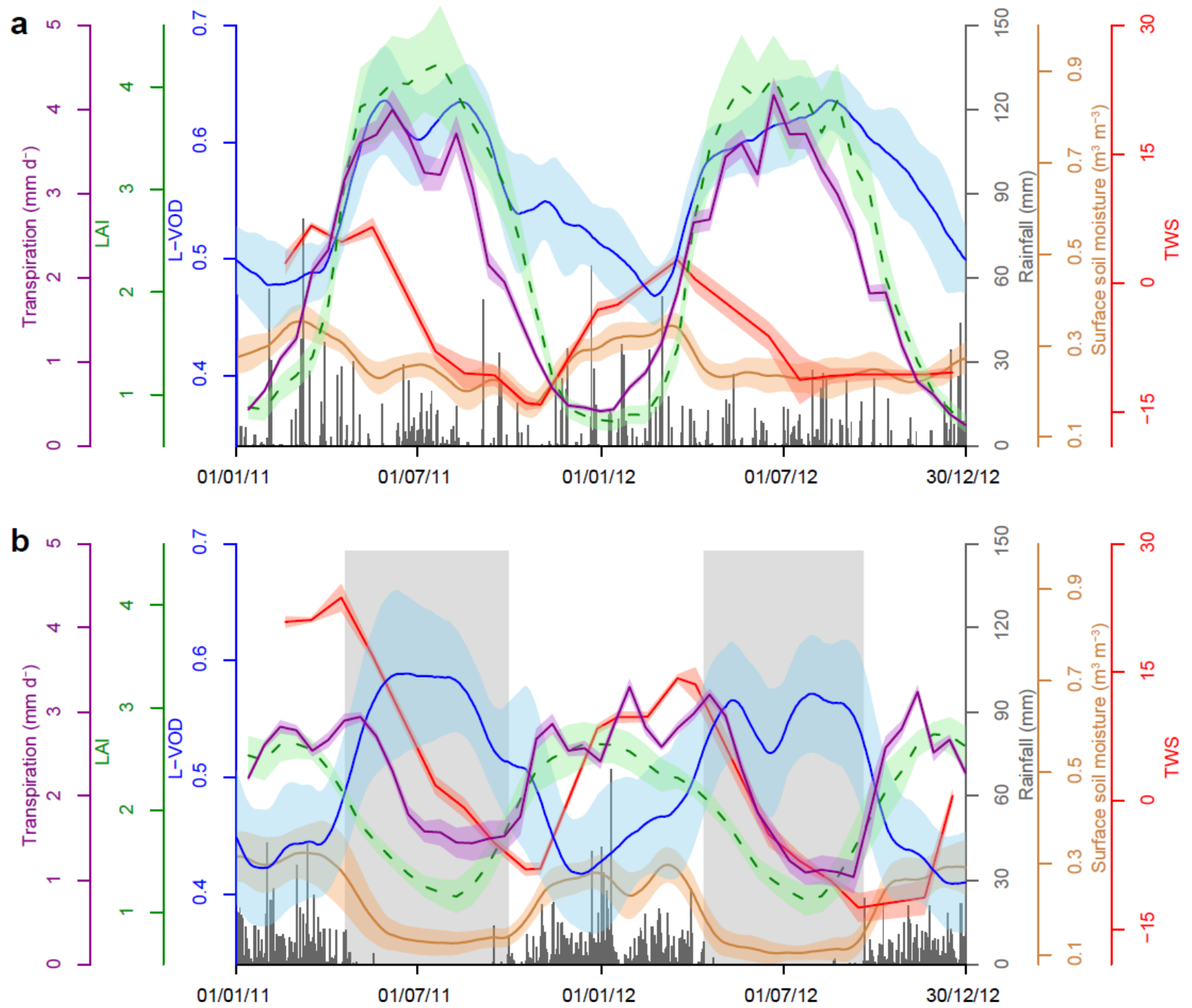

162 Figure 5: Seasonal water balance in two contrasting ecosystems. The time series (2011-2012) of plant water storage (L-

163 VOD), terrestrial groundwater storage anomaly (TWS), surface soil moisture, rainfall, transpiration, and foliar phenology

164 (LAI) for a $1^{\circ} \times 1^{\circ}$ area in the (a) southeastern US temperate forests (centred at $33.5^{\circ} \mathrm{N}, 85.5^{\circ} \mathrm{W}$ ) and (b) African tropical Miombo woodlands (centred at $\left.11.5^{\circ} \mathrm{S}, 18.5^{\circ} \mathrm{E}\right)$. The coloured shaded curves represent the standard deviations $(\mathrm{n}=16$ for all except TWS where $n=3$ ). The grey shaded rectangles in (b) indicate the dry seasons. weeks before the onset of the rainy season, confirming the pre-rain green-up reported by previous studies ${ }^{39}$. 
measurements (for the tree species Brachystegia spiciformis) in this region ${ }^{40}$. SM remained at the lowest level during the entire dry season with almost no rainfall, but TWS decreased continuously, suggesting that deep groundwater was used by trees during the dry season ${ }^{41}$. In contrast, L-VOD increased at the beginning of the dry season, peaked around the time when LAI was lowest, and then decreased when LAI increased again. During the rainy season, both transpiration and SM remained high, TWS was continuously recharged, and L-VOD increased during the latter part of the rainy season. These results together indicate a critical role of the stored plant water on buffering the seasonal dynamics of water supply and demand in these tropical dry woodlands.

An endogenous whole-plant control of foliar phenology has been documented in some seasonally dry tropical tree species $^{42,43}$, where water stored in the stems directly contributes to the foliar emergence during the pre-rain greenup period ${ }^{44,45}$, which may explain the decrease in L-VOD at the end of the dry season. The cambium of Miombo trees mainly grows during a short period late in the rainy season ${ }^{46,47}$, when L-VOD increased. The continued increase in L-VOD at the end of the rainy season and at the beginning of the dry season is consistent with the reduced loss of transpirational water associated with leaf shedding that enables the rehydration of stem tissues and the subsequent foliar emergence ${ }^{44,46}$. The Miombo woodland region was the largest hot-spot area characterized by long time lags between L-VOD and LAI, but the northern African woodlands and the Brazilian Cerrado have similar patterns as well (Extended Data Fig. 11).

The specific seasonal behaviour of various water cycle components within each region indicate the adaptation of plants to local climatic conditions (e.g., seasonal variations in rainfall, temperature, and photosynthetic active radiation) and abiotic conditions (e.g. soil types and soil water supply) at the ecosystem scale. The spatial heterogeneity in species composition needs to be considered for further in-depth hydrological/physiological interpretations on the large-footprint satellite signal because closely located tree species sharing the same environmental conditions can be characterized by different hydraulic strategies, e.g., between soft wood species and hard wood species ${ }^{44}$. At the same time, different species across ecosystems may have similar hydraulic mechanisms as root hydraulic lift and redistribution of deep ground water were identified in both temperate forests and tropical woodlands ecosystems ${ }^{48,49}$. 
Our study provides the first observational evidence of global differences in the interaction between plant water storage and foliar phenology. The satellite-based L-VOD product allows for an efficient and repeated monitoring of changes in large-scale plant water storage, which is highly valuable for mapping and understanding spatial differences in plant hydraulic strategies ${ }^{2,50}$. Furthermore, the lag analyses between satellite-observed L-VOD and LAI/TWS as well as the resulting spatial patterns in relation to vegetation density and types provide a convenient way to condense patters of plant water storage across the globe, which can be used to parameterize and test relevant process-based eco-hydrological and other earth system models upon reproducing observed behaviors. With future expansion of the time-series covered by L-band satellite microwave observations including also improvements of the spatial coverage over RFI influenced $\operatorname{areas}^{23}$, the L-VOD product will be a strong complementary to the VOD products from higher frequencies and the greenness-/productivity-oriented optical satellite records for studying ecosystem responses to climate change.

\section{Methods}

\section{Data sets}

The SMOS satellite covers the earth surface nearly daily with both ascending (6 am) and descending (6 pm) overpasses since the beginning of 2010. The whole system underwent the so-called commissioning phase until June 2010 when various operation modes were tested, leading to less observations in comparison to the following years. Therefore, we used data during the period of 2011-2016. We selected the ascending observations as plant water storage usually peaks at dawn. The SMOS-IC algorithm ${ }^{23}$ was applied to retrieve L-VOD and SM simultaneously from SMOS observations, without any external vegetation products as inputs, so the current LVOD retrievals (version 103) were independent from any other vegetation indices. Conversely to other SMOS products (e.g., Level 2 and Level 3) ${ }^{51}$, no remotely sensed LAI data were used in the SMOS-IC retrieval process to estimate L-VOD over heterogeneous pixels, neither SM data from ECMWF (European Centre for MediumRange Weather Forecasts) were used to estimate SM over the forest fraction in mixed pixels. The native SMOS spatial resolution ( $3 \mathrm{~dB}$ footprint) varies between $\sim 27$ and $\sim 55 \mathrm{~km}$ depending on the incidence angles (observations 
at high incidence angles were filtered out in SMOS-IC). The data were originally projected in the standard EASE2 grid at a $25 \mathrm{~km}$ spatial resolution and we further converted it into a geographical projection at a $0.25^{\circ}$ spatial resolution.

The LAI data were generated from the standard MODIS Collection 6 LAI products (MOD15 and MYD15; 8-day composites at a $0.05^{\circ}$ spatial resolution) from Terra and Aqua for 2011-2016 ${ }^{52}$. The MODIS LAI algorithm accounts for sun-sensor geometry. We refined the raw LAI data into 16-day composites by averaging the cloudfree observations indicated by the quality flag information to minimize the influences from environmental contamination, e.g. clouds, aerosols, shadows, and poor sun-sensor geometries. All high-quality LAI data were then resampled to $0.25^{\circ}$ by averaging and linearly interpolating to a daily time step to match the spatial and temporal resolutions of the L-VOD data.

The TWS data were from the Gravity Recovery and Climate Experiment (GRACE) satellites, which measure the changes in the Earth's gravitational field that are highly correlated with changes in both surface and sub-surface water storage ${ }^{53,54}$. The monthly GRACE TWS products are provided in three solutions by the GeoForschungsZentrum Potsdam (GFZ), the Center for Space Research at the University of Texas (CSR), and the Jet Propulsion Laboratory (JPL) at a $1^{\circ}$ spatial resolution. We used the average of the three products and the associated standard deviations, as suggested by recent studies ${ }^{55}$. Only 10 observations were available for 2011 and 2012 due to battery management.

The X-VOD data were from the land parameter data record (LPDR v2) developed by the Numerical Terradynamic Simulation Group at The University of Montana ${ }^{35}$. The X-VOD was retrieved from the AMSR sensors at a microwave frequency of $10.7 \mathrm{GHz}$ for both ascending $(1.30 \mathrm{pm})$ and descending $(1.30 \mathrm{am})$ overpasses at a spatial resolution of $0.25^{\circ}$. We selected the descending X-VOD retrievals for 2011-2016. The same principle ( $\omega-\tau$ model) was used for retrieving X-VOD from AMSR microwave observations as for the SMOS-IC L-VOD retrieval algorithm, which was also independent from optical vegetation indices.

The data for tree cover fractions were produced by Chiba University for $2008^{27}$, since this dataset outperforms the MODerate-resolution Imaging Spectroradiometer (MODIS) Vegetation Continuous Fields product (MOD44B) for 
245 African drylands where MOD44B largely underestimates the woody cover ${ }^{56,57}$. Tree height data was from spaceborne light detection and ranging (lidar) data obtained by the Geoscience Laser Altimeter System (GLAS) ${ }^{58}$.

247 The rainfall data were from the Tropical Rainfall Measurement Mission (TRMM) 3B42 v7 daily product ${ }^{59}$, which 248 were estimated from satellite measurements at a $0.25^{\circ}$ spatial resolution.

The transpiration data were from estimates by the Global Land Evaporation Amsterdam Model (GLEAM) v3.1a, which used a set of algorithms for estimating a series of water-cycle components (without plant water storage) at a daily time step and $0.25^{\circ}$ spatial resolution ${ }^{60,61}$.

\section{Analysis of seasonal lag}

253

254

255

256

257

258

259

260

261

262

263

264

265

266

267

268

269

We concatenated the six-year (2011-2016) data into a mean yearly daily time series for each pixel to obtain a clear and reliable seasonality in L-VOD (see an example pixel in Extended Data Fig. 1a and b). The median of raw LVOD retrievals from the same day of the year for 2011-2016 was first used to form an average seasonality. Second, a 30-day moving median was determined, followed by calculating the anomalies between the raw data and the median curve. The data points larger/smaller than the median curve $+/$ - the standard deviation of the anomalies were defined as outliers and thus removed from the subsequent analysis (de-noise). Finally, a 30-day movingaverage curve was calculated for the valid data points. The seasonality of LAI and X-VOD were determined using the same method as for L-VOD.

For the L-VOD seasonality, we accounted for both the data noise and the actual seasonal variations in plant water storage, using the ratio between the seasonal amplitude and the standard deviation of the anomalies as an indicator of the intra-annual variability (Extended Data Fig. 1c). Pixels with a ratio $>1.2$ (a buffer of $20 \%$ standard deviation) were deemed to be characterized by a clear seasonality, despite the data noise, and were thus selected for further lag analysis with the LAI seasonality, and pixels with a ratio $\leq 1.2$ were deemed to have no clear seasonal patterns in L-VOD. Double growing seasons will introduce large uncertainties in quantifying the time lag, so we limited the analysis to pixels characterized by a single growing season in both L-VOD and LAI seasonality. We normalized the mean seasonality of each pixel to $0-1$ by subtracting the minimum value and then dividing by the amplitude, and identified pixels with only two 0.5 crossing points as being characterized by a single growing season ${ }^{62}$. 
271 The SMOS-IC algorithm applies a constant soil surface roughness and effective scattering albedo over time and 272 use an effective temperature input from ECMWF estimates ${ }^{23,24}$, which will introduce uncertainties in the L-VOD 273 retrievals. We performed a series of sensitivity analyses focusing on the possible influences from these uncertainty 274 settings/sources on the L-VOD seasonal pattern retrieved from the SMOS-IC algorithm over the Miombo region, 275 where L-VOD peaks during the dry season. Specifically, we applied various value settings of these input parameters covering a dynamic range larger than the expected ones to examine the possible resulting changes in the L-VOD seasonality.

Soil surface roughness may change in relation to agricultural practices, but very unlikely over natural environmental conditions at the satellite footprint scale as for the Miombo region. The roughness parameter (HR) used in the SMOS-IC algorithm is 0.3 for the forested pixels in the Miombo region ${ }^{63,64}$. We compared the L-VOD retrievals over this region by setting HR to 0.2 and 0.4 , respectively, but found little difference in the seasonal cycle from a setting of 0.3 used in the original SMOS-IC algorithm (Extended Data Figure 9). Because the seasonal changes in soil surface roughness are expected to be much smaller than an HR range of 0.2 , they will have very limited influence on the observed L-VOD seasonal trends.

Canopy leaves have dominant effects on the emissivity and effective scattering albedo of deciduous forests at higher frequencies $(>6 \mathrm{GHz})$, but the leaf effects are limited at L-band as suggested by several studies which show that stems and branches are the main elements contributing to forest emissivity at L-band ${ }^{13-15,63}$. Therefore, in the SMOS-IC algorithm, a constant effective scattering albedo (Omega) value of 0.06 was used for the Miombo woodlands although dominated by a deciduous forest type with a clear annual cycle in the canopy leaf conditions $^{23,65,66}$. To test the influence from an expected small change in the effective albedo (lower than 0.01) on the retrieved L-VOD values, we ran the SMOS-IC algorithm by setting the Omega value to 0.05 and 0.07 , respectively over the Miombo region ${ }^{67}$. Again, the results show little difference in the retrieved L-VOD seasonal patterns between these different settings (Extended Data Figure 10). Therefore, using a constant effective scattering albedo of 0.06 in the SMOS-IC algorithm will have a very limited influence on the observed L-VOD seasonal trends over the Miombo woodlands. 
The ECWMF soil and vegetation temperatures used to estimate the effective surface temperature (Ts) in the SMOS-IC algorithm ${ }^{68}$ may have a root mean square deviation as high as a few Kelvin ${ }^{69,70}$. We applied a drastic approach to investigate its possible impacts on the L-VOD seasonal patterns, that is, setting a constant effective temperature (Ts) value over the course of the year. Two constant values (291 K and 295K) with a range of $4 \mathrm{~K}$ were considered based on the observed average value ( 293 K) and standard deviation ( 2 K) of seasonal changes in Ts over the Miombo region. Results were compared to L-VOD retrievals considering dynamic ECMWF estimations of Ts, as applied in the SMOS-IC algorithm. Again, little difference in the retrieved L-VOD values from the different Ts settings were observed (Extended Data Figure 11). This suggests a relatively small impact on L-VOD seasonality from possible uncertainties in the estimates of Ts computed from ECMWF data, which may be attributable to the narrow seasonal changes in temperature over the Miombo region. Therefore, the uncertainties and possible erroneous trends associated with the ECMWF temperature products cannot explain the specific L-VOD signatures observed in this region.

\section{Analysis of seasonal water balance}

A variety of water-cycle components were plotted together to investigate the water balance at a US temperate forest site and a tropical Miombo woodland site. Specifically, the SMOS L-VOD and SM data were smoothed using a moving-average method (window size of 30 days). Daily estimates of transpiration were aggregated to a 16-day mean to match the MODIS LAI temporal resolution for better visualization. The onset of the rainy season (or end of the dry season) in the tropical Miombo site was determined following the criteria ${ }^{39}$ : (1) a total rainfall of $25 \mathrm{~mm}$ within 10 successive days, followed by (2) a total rainfall $>20 \mathrm{~mm}$ within 20 days. The start of the dry season (or end of the rainy season) was defined as the last day with rainfall $>10 \mathrm{~mm}$.

\section{Data availability}

The SMOS L-VOD and SM products are available upon request and will be made publicly available by CATDS (Centre aval de traitement des données SMOS). MODIS LAI data are available from http://sites.bu.edu/cliveg. Anomalous GRACE data for terrestrial groundwater storage are available from https://grace.jpl.nasa.gov. X-VOD data can be downloaded from www.ntsg.umt.edu. Tree cover data are available from 
https://globalmaps.github.io/ptc.html. Tree height data can be downloaded from

322 https://webmap.ornl.gov/ogc/dataset.jsp?ds $\mathrm{id}=10023$. The global inundation map is available upon request at

323 www.estellus.fr/index.php?static13/giems-d15. TRMM rainfall data are available from https://pmm.nasa.gov.

324 Transpiration data can be downloaded from https://www.gleam.eu.

\section{Code availability}

326 The code used for seasonal lag analyses in this study was deposited in GitHub: 327 https://github.com/fengtian2017/SMOS-L-VOD-seasonality

\section{References}

$3301 \quad$ Street, H. E. \& Cockburn, W. Plant metabolism. (Elsevier, 2014).

3312 Sack, L. et al. Plant hydraulics as a central hub integrating plant and ecosystem function: meeting report for 'Emerging Frontiers in Plant Hydraulics' (Washington, DC, May 2015). Plant, Cell \& Environment 39, 2085-2094, doi:10.1111/pce.12732 (2016).

3343 Lin, Y.-S. et al. Optimal stomatal behaviour around the world. Nature Clim. Change 5, 459-464, 335 doi:10.1038/nclimate2550 (2015).

3364 De Boer, A. H. \& Volkov, V. Logistics of water and salt transport through the plant: structure and functioning of the xylem. Plant, Cell \& Environment 26, 87-101, doi:10.1046/j.1365-3040.2003.00930.x (2003).

3395 Chave, J. et al. Towards a worldwide wood economics spectrum. Ecology Letters 12, 351-366, 340 doi:10.1111/j.1461-0248.2009.01285.x (2009).

3416 Hartzell, S., Bartlett, M. S. \& Porporato, A. The role of plant water storage and hydraulic strategies in 342 relation to soil moisture availability. Plant and Soil, doi:10.1007/s11104-017-3341-7 (2017).

3437 Matheny, A. M. et al. Observations of stem water storage in trees of opposing hydraulic strategies. $344 \quad$ Ecosphere 6, 1-13, doi:10.1890/ES15-00170.1 (2015). 
$3458 \quad$ Jones, H. G. Monitoring plant and soil water status: established and novel methods revisited and their

346 relevance to studies of drought tolerance. Journal of Experimental Botany 58, 119-130,

347 doi:10.1093/jxb/erl118 (2007).

3489 Wullschleger, S. D., Meinzer, F. C. \& Vertessy, R. A. A review of whole-plant water use studies in tree.

Tree Physiology 18, 499-512, doi:10.1093/treephys/18.8-9.499 (1998).

35010 Goldstein, G. et al. Stem water storage and diurnal patterns of water use in tropical forest canopy trees.

$351 \quad$ Plant, Cell \& Environment 21, 397-406, doi:10.1046/j.1365-3040.1998.00273.x (1998).

35211 Jackson, T. J. \& Schmugge, T. J. Vegetation effects on the microwave emission of soils. Remote Sensing

353 of Environment 36, 203-212, doi:http://dx.doi.org/10.1016/0034-4257(91)90057-D (1991).

35412 Griend, A. A. V. d. \& Wigneron, J. P. The b-factor as a function of frequency and canopy type at H-

355 polarization. IEEE Transactions on Geoscience and Remote Sensing 42, 786-794,

356 doi:10.1109/TGRS.2003.821889 (2004).

35713 Guglielmetti, M. et al. Measured microwave radiative transfer properties of a deciduous forest canopy.

$358 \quad$ Remote Sensing of Environment 109, 523-532, doi:http://dx.doi.org/10.1016/j.rse.2007.02.003 (2007).

35914 Santi, E., Paloscia, S., Pampaloni, P. \& Pettinato, S. Ground-Based Microwave Investigations of Forest

$360 \quad$ Plots in Italy. IEEE Transactions on Geoscience and Remote Sensing 47, 3016-3025,

361 doi:10.1109/TGRS.2009.2021613 (2009).

36215 Ferrazzoli, P., Guerriero, L. \& Wigneron, J. P. Simulating L-band emission of forests in view of future

363 satellite applications. IEEE Transactions on Geoscience and Remote Sensing 40, 2700-2708,

364 doi:10.1109/TGRS.2002.807577 (2002).

36516 Sternberg, M. \& Shoshany, M. Aboveground biomass allocation and water content relationships in

366 Mediterranean trees and shrubs in two climatological regions in Israel. Plant Ecology 157, 173-181,

367 doi:10.1023/a:1013916422201 (2001).

36817 Jones, M. O., Jones, L. A., Kimball, J. S. \& McDonald, K. C. Satellite passive microwave remote

sensing for monitoring global land surface phenology. Remote Sensing of Environment 115, 1102-1114, doi:http://dx.doi.org/10.1016/j.rse.2010.12.015 (2011). 
Tian, F. et al. Remote sensing of vegetation dynamics in drylands: Evaluating vegetation optical depth (VOD) using AVHRR NDVI and in situ green biomass data over West African Sahel. Remote Sensing of Environment 177, 265-276, doi:http://dx.doi.org/10.1016/j.rse.2016.02.056 (2016).

Momen, M. et al. Interacting Effects of Leaf Water Potential and Biomass on Vegetation Optical Depth. Journal of Geophysical Research: Biogeosciences, n/a-n/a, doi:10.1002/2017JG004145 (2017).

Konings, A. G. \& Gentine, P. Global variations in ecosystem-scale isohydricity. Global Change Biology 23, 891-905, doi:10.1111/gcb.13389 (2016).

Konings, A. G., Williams, A. P. \& Gentine, P. Sensitivity of grassland productivity to aridity controlled

Kerr, Y. H. et al. The SMOS Mission: New Tool for Monitoring Key Elements ofthe Global Water Cycle. Proceedings of the IEEE 98, 666-687, doi:10.1109/JPROC.2010.2043032 (2010). Depth Product. Remote Sensing 9, 457 (2017).

Wigneron, J. P. et al. L-band Microwave Emission of the Biosphere (L-MEB) Model: Description and calibration against experimental data sets over crop fields. Remote Sensing of Environment 107, 639655, doi:http://dx.doi.org/10.1016/j.rse.2006.10.014 (2007).

Oliva, R. et al. SMOS Radio Frequency Interference Scenario: Status and Actions Taken to Improve the RFI Environment in the 1400-1427-MHz Passive Band. IEEE Transactions on Geoscience and Remote Sensing 50, 1427-1439, doi:10.1109/tgrs.2012.2182775 (2012).

Olson, D. M. et al. Terrestrial Ecoregions of the World: A New Map of Life on Earth. BioScience 51, 933-938, doi:10.1641/0006-3568(2001)051[0933:TEOTWA]2.0.CO;2 (2001). 
29 Rahmoune, R. et al. SMOS Retrieval Results Over Forests: Comparisons With Independent Measurements. Ieee J-Stars 7, 3858-3866, doi:10.1109/JSTARS.2014.2321027 (2014).

30 Konings, A. G., Piles, M., Das, N. \& Entekhabi, D. L-band vegetation optical depth and effective scattering albedo estimation from SMAP. Remote Sensing of Environment 198, 460-470, doi:http://dx.doi.org/10.1016/j.rse.2017.06.037 (2017).

31 Morris, H. et al. A global analysis of parenchyma tissue fractions in secondary xylem of seed plants. New Phytologist 209, 1553-1565, doi:10.1111/nph.13737 (2016).

32 Meinzer, F. C., Johnson, D. M., Lachenbruch, B., McCulloh, K. A. \& Woodruff, D. R. Xylem hydraulic safety margins in woody plants: coordination of stomatal control of xylem tension with hydraulic capacitance. Functional Ecology 23, 922-930, doi:10.1111/j.1365-2435.2009.01577.x (2009).

33 M T Tyree, a. \& Sperry, J. S. Vulnerability of Xylem to Cavitation and Embolism. Annual Review of Plant Physiology and Plant Molecular Biology 40, 19-36, doi:10.1146/annurev.pp.40.060189.000315 (1989).

4 Fan, Y., Miguez-Macho, G., Jobbágy, E. G., Jackson, R. B. \& Otero-Casal, C. Hydrologic regulation of plant rooting depth. Proceedings of the National Academy of Sciences 114, 10572-10577, doi:10.1073/pnas.1712381114 (2017).

Du, J. et al. A global satellite environmental data record derived from AMSR-E and AMSR2 microwave Earth observations. Earth System Science Data 9, 791-808, doi:10.5194/essd-9-791-2017 (2017).

Tapley, B. D., Bettadpur, S., Ries, J. C., Thompson, P. F. \& Watkins, M. M. GRACE Measurements of Mass Variability in the Earth System. Science 305, 503-505, doi:10.1126/science.1099192 (2004).

Pokhrel, Y. N., Fan, Y., Miguez- Macho, G., Yeh, P. J. F. \& Han, S. C. The role of groundwater in the Amazon water cycle: 3 . Influence on terrestrial water storage computations and comparison with GRACE. Journal of Geophysical Research: Atmospheres 118, 3233-3244, doi:doi:10.1002/jgrd.50335 (2013).

Köcher, P., Horna, V. \& Leuschner, C. Stem water storage in five coexisting temperate broad-leaved tree species: significance, temporal dynamics and dependence on tree functional traits. Tree Physiology 33, 817-832, doi:10.1093/treephys/tpt055 (2013). 
42539 Ryan, C. M., Williams, M., Grace, J., Woollen, E. \& Lehmann, C. E. R. Pre-rain green-up is ubiquitous 426 across southern tropical Africa: implications for temporal niche separation and model representation.

427

428

429

430

431

432 New Phytologist 213, 625-633, doi:10.1111/nph.14262 (2017).

40 Choinski, J. J. S. \& Johnson, J. M. Changes in photosynthesis and water status of developing leaves of Brachystegia spiciformis Benth. Tree Physiology 13, 17-27, doi:10.1093/treephys/13.1.17 (1993).

41 Guan, K. et al. Terrestrial hydrological controls on land surface phenology of African savannas and woodlands. Journal of Geophysical Research: Biogeosciences 119, 1652-1669, doi:10.1002/2013JG002572 (2014).

Reich, P. B. Phenology of tropical forests: patterns, causes, and consequences. Canadian Journal of Botany 73, 164-174, doi:10.1139/b95-020 (1995).

43 Williams, R. J., Myers, B. A., Muller, W. J., Duff, G. A. \& Eamus, D. Leaf phenology of woody species in a north australian tropical savanna. Ecology 78, 2542-2558, doi:10.1890/00129658(1997)078[2542:LPOWSI]2.0.CO;2 (1997).

44 Borchert, R. Soil and Stem Water Storage Determine Phenology and Distribution of Tropical Dry Forest Trees. Ecology 75, 1437-1449, doi:10.2307/1937467 (1994).

45 Chapotin, S. M., Razanameharizaka, J. H. \& Holbrook, N. M. Baobab trees (Adansonia) in Madagascar use stored water to flush new leaves but not to support stomatal opening before the rainy season. New Phytologist 169, 549-559, doi:10.1111/j.1469-8137.2005.01618.x (2006).

46 Trouet, V., Mukelabai, M., Verheyden, A. \& Beeckman, H. Cambial Growth Season of BreviDeciduous Brachystegia spiciformis Trees from South Central Africa Restricted to Less than Four Months. PLOS ONE 7, e47364, doi:10.1371/journal.pone.0047364 (2012).

Elifuraha, E., Nöjd, P. \& Mbwambo, L. Short term growth of miombo tree species at Kitulangalo. (Working Papers of the Finnish Forest Research Institute 98: 37-45, 2008).

8 Domec, J. C. et al. Hydraulic redistribution of soil water by roots affects whole- stand evapotranspiration and net ecosystem carbon exchange. New Phytologist 187, 171-183, doi:doi:10.1111/j.1469-8137.2010.03245.x (2010). 
$49 \mathrm{Yu}, \mathrm{K} . \&$ D'Odorico, P. Hydraulic lift as a determinant of tree-grass coexistence on savannas. New Phytologist 207, 1038-1051, doi:doi:10.1111/nph.13431 (2015).

$45350 \quad$ Huang, C.-W. et al. The effect of plant water storage on water fluxes within the coupled soil-plant

454

455

456

457

458

459

460

461

462

463

464

465

466

467

$468 \quad 56$

469

$470 \quad 57$

471

472

473

474

475 system. New Phytologist 213, 1093-1106, doi:10.1111/nph.14273 (2017).

51 Kerr, Y. H. et al. The SMOS Soil Moisture Retrieval Algorithm. IEEE Transactions on Geoscience and Remote Sensing 50, 1384-1403, doi:10.1109/TGRS.2012.2184548 (2012).

52 Myneni, R. B. et al. Global products of vegetation leaf area and fraction absorbed PAR from year one of MODIS data. Remote Sensing of Environment 83, 214-231, doi:https://doi.org/10.1016/S0034$\underline{4257(02) 00074-3}$ (2002).

53 Strassberg, G., Scanlon, B. R. \& Chambers, D. Evaluation of groundwater storage monitoring with the GRACE satellite: Case study of the High Plains aquifer, central United States. Water Resources Research 45, n/a-n/a, doi:10.1029/2008WR006892 (2009).

54 Reager, J. T. et al. A decade of sea level rise slowed by climate-driven hydrology. Science 351, 699-703, doi:10.1126/science.aad8386 (2016).

55 Sakumura, C., Bettadpur, S. \& Bruinsma, S. Ensemble prediction and intercomparison analysis of GRACE time-variable gravity field models. Geophysical Research Letters 41, 1389-1397, doi:10.1002/2013GL058632 (2014).

56 Brandt, M. et al. Human population growth offsets climate-driven increase in woody vegetation in subSaharan Africa. Nature Ecology \& Evolution 1, 0081, doi:10.1038/s41559-017-0081 (2017).

57 Brandt, M. et al. Woody plant cover estimation in drylands from Earth Observation based seasonal metrics. Remote Sensing of Environment 172, 28-38, doi:http://dx.doi.org/10.1016/j.rse.2015.10.036 (2016).

58 Simard, M., Pinto, N., Fisher, J. B. \& Baccini, A. Mapping forest canopy height globally with spaceborne lidar. Journal of Geophysical Research: Biogeosciences 116, doi:doi:10.1029/2011JG001708 (2011). 
47659 Huffman, G. J. et al. The TRMM Multisatellite Precipitation Analysis (TMPA): Quasi-Global,

477

478

479

480

481

482

483

484

485

486

487

488

489

490

491

492

493

494

495

496

497

498

499

500
Multiyear, Combined-Sensor Precipitation Estimates at Fine Scales. Journal of Hydrometeorology 8, 3855, doi:10.1175/jhm560.1 (2007).

60 Martens, B. et al. GLEAM v3: satellite-based land evaporation and root-zone soil moisture. Geosci. Model Dev. 10, 1903-1925, doi:10.5194/gmd-10-1903-2017 (2017).

61 Miralles, D. G. et al. Global land-surface evaporation estimated from satellite-based observations. Hydrol. Earth Syst. Sci. 15, 453-469, doi:10.5194/hess-15-453-2011 (2011).

62 Garonna, I. et al. Strong contribution of autumn phenology to changes in satellite-derived growing season length estimates across Europe (1982-2011). Global Change Biology 20, 3457-3470, doi:10.1111/gcb.12625 (2014).

63 Parrens, M. et al. Global-scale surface roughness effects at L-band as estimated from SMOS observations. Remote Sensing of Environment 181, 122-136, doi:https://doi.org/10.1016/j.rse.2016.04.006 (2016).

64 Fernandez-Moran, R. et al. A new calibration of the effective scattering albedo and soil roughness parameters in the SMOS SM retrieval algorithm. International Journal of Applied Earth Observation and Geoinformation 62, 27-38, doi:https://doi.org/10.1016/j.jag.2017.05.013 (2017).

65 Vittucci, C., Ferrazzoli, P., Richaume, P. \& Kerr, Y. Effective Scattering Albedo of Forests Retrieved by SMOS and a Three-Parameter Algorithm. IEEE Geoscience and Remote Sensing Letters 14, 2260-2264, doi:10.1109/LGRS.2017.2761124 (2017).

66 Parrens, M. et al. Estimation of the L-Band Effective Scattering Albedo of Tropical Forests Using SMOS Observations. IEEE Geoscience and Remote Sensing Letters 14, 1223-1227, doi:10.1109/LGRS.2017.2703637 (2017).

67 Du, J., Kimball, J. S. \& Jones, L. A. Passive Microwave Remote Sensing of Soil Moisture Based on Dynamic Vegetation Scattering Properties for AMSR-E. IEEE Transactions on Geoscience and Remote Sensing 54, 597-608, doi:10.1109/TGRS.2015.2462758 (2016). 
50168 Wigneron, J. P. et al. Modelling the passive microwave signature from land surfaces: A review of recent results and application to the L-band SMOS \&amp; SMAP soil moisture retrieval algorithms. Remote Sensing of Environment 192, 238-262, doi:http://dx.doi.org/10.1016/j.rse.2017.01.024 (2017).

Holmes, T. R. H., Jackson, T. J., Reichle, R. H. \& Basara, J. B. An assessment of surface soil temperature products from numerical weather prediction models using ground- based measurements. Water Resources Research 48, doi:doi:10.1029/2011WR010538 (2012). Albergel, C. et al. Soil temperature at ECMWF: An assessment using ground- based observations. Journal of Geophysical Research: Atmospheres 120, 1361-1373, doi:doi:10.1002/2014JD022505 (2015).

510

\section{Acknowledgements}

512 We thank Etienne Fluet Chouinard, Filipe Aires and Catherine Prigent for providing the global inundation map. 513 This work was funded by CNES (Centre National d'Etudes Spatiales) through the Science TOSCA (Terre Océan 514 Surfaces Continentales et Atmosphère) program, European Space Agency (ESA) Support to Science Element 515 (STSE) programme, and SMOS Export Support Laboratory (ESL). F.T. and R.F. acknowledge the funding from 516 the Danish Council for Independent Research (DFF) Grant ID: DFF - 6111-00258. F.T. is also the recipient of the 517 European Union's Horizon 2020 research and innovation program under the Marie Skłodowska-Curie Grant 518 agreement (project number 746347). P.C. and J.P. acknowledge funding from the European Research Council 519 Synergy grant ERC-2013-SyG-610028 IMBALANCE-P. T.T. was funded by the Swedish national space board 520 (Dnr: 95/16). P.C. acknowledges additional support from the ANR ICONV CLAND grant. J.C. has benefited from

521 "Investissement d'Avenir" grants managed by the French Agence Nationale de la Recherche (CEBA, ref. ANR522 10-LABX-25-01 and TULIP, ref. ANR-10-LABX-0041), and from TOSCA funds from the CNES. 
524 F.T., J.P.W., M.B., and R.F. designed the study with inputs from P.C., J.C., J.P., and A.R.. J.P.W., Y.K., A.M., 525 N.R-F., and A.A.Y. prepared the SMOS-IC data and performed the sensitivity analyses. C.C. and R.B.M. prepared 526 the MODIS LAI data. F.T. performed data analyses. The results were interpreted by J.P.W., A.R., J.C., F.T., P.C., 527 J.P., J.O., J.C.D., X.T., N.R-F., A.M., T.T., A.A.Y. and R.F.. F.T. drafted the manuscript with editing by P.C., J.P., 528 J.O., J.C. and contributions from all co-authors.

529 The authors declare no competing financial interests.

530 Materials and correspondence should be addressed to F.T. (feng.tian@ @ nateko.lu.se; ftian2012@ gmail.com) and 531 J.P.W. (jean-pierre.wigneron@inra.fr). 
a

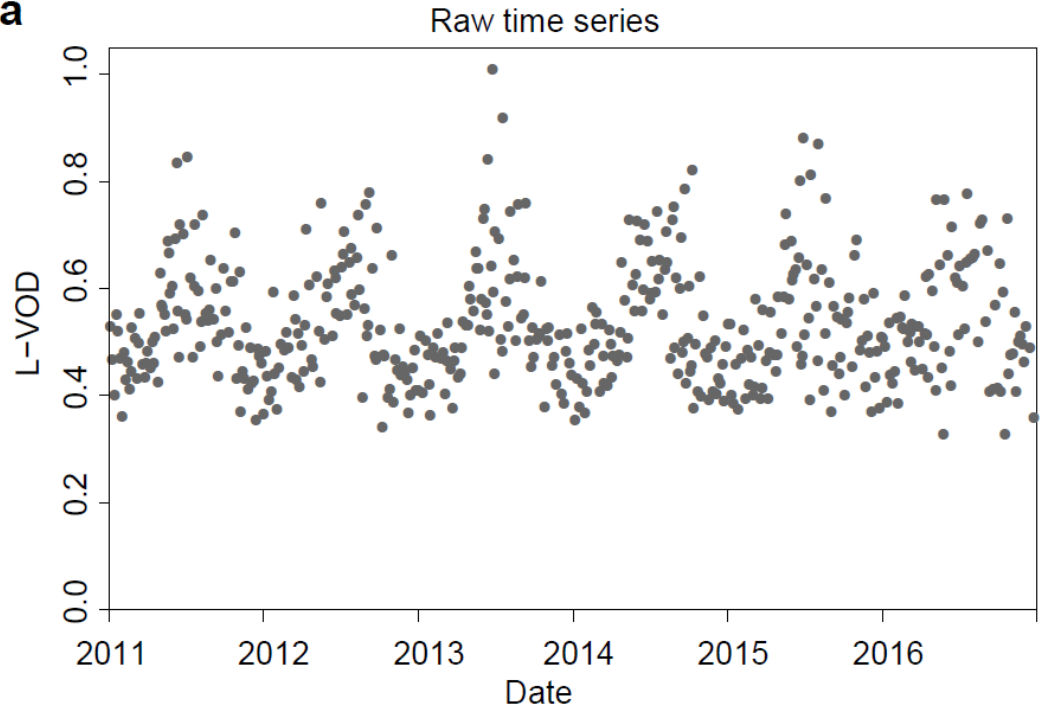

b

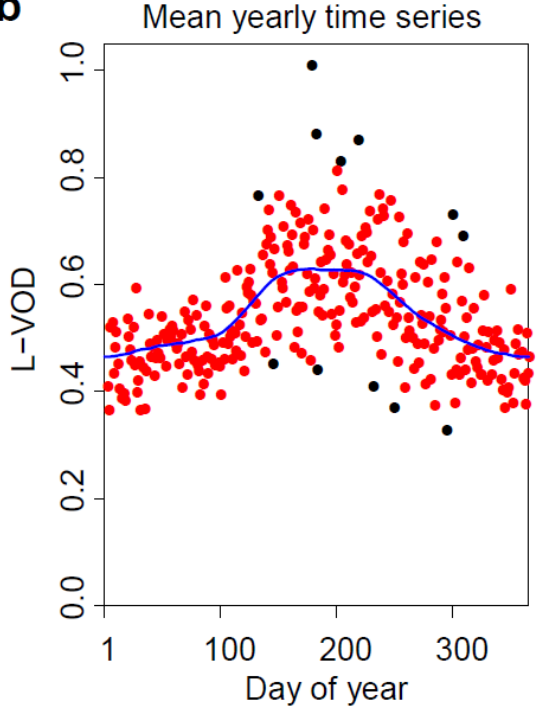

C Ratio between seasonal amplitude and standard deviation

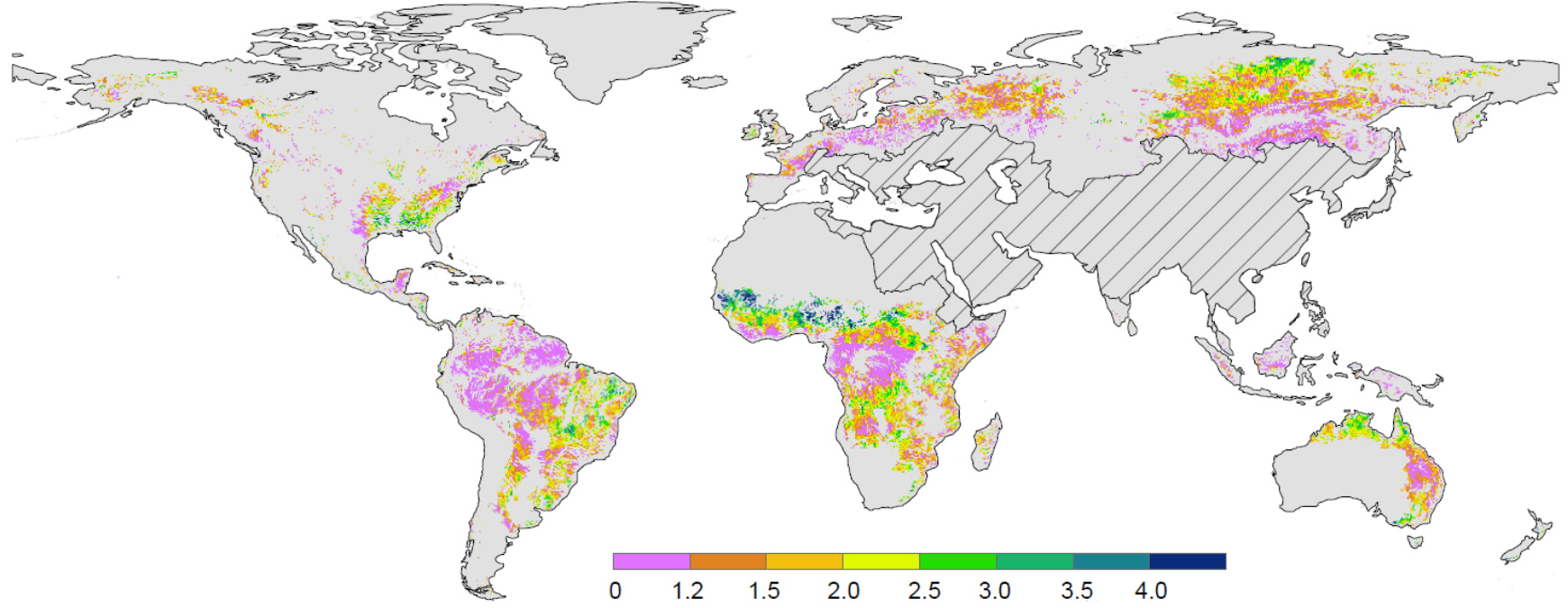

533 Extended Data Figure 1: SMOS-IC L-VOD data processing. a, The raw L-VOD time series for 2011-2016 from an 534 example pixel (location: $11.25^{\circ} \mathrm{S}, 18.25^{\circ} \mathrm{E}$ ). b, The mean L-VOD seasonality of the example pixel. The red points were 535 selected for further smoothing and the calculation of standard deviations, and the black points were rejected as outliers. The blue curve is the moving average of the red points. $\mathbf{c}$, Global distribution of the ratio between seasonal amplitude and standard deviation. Masked areas are explained in the text. The ratio between seasonal amplitude and standard deviation for the example pixel is 2.3 . 


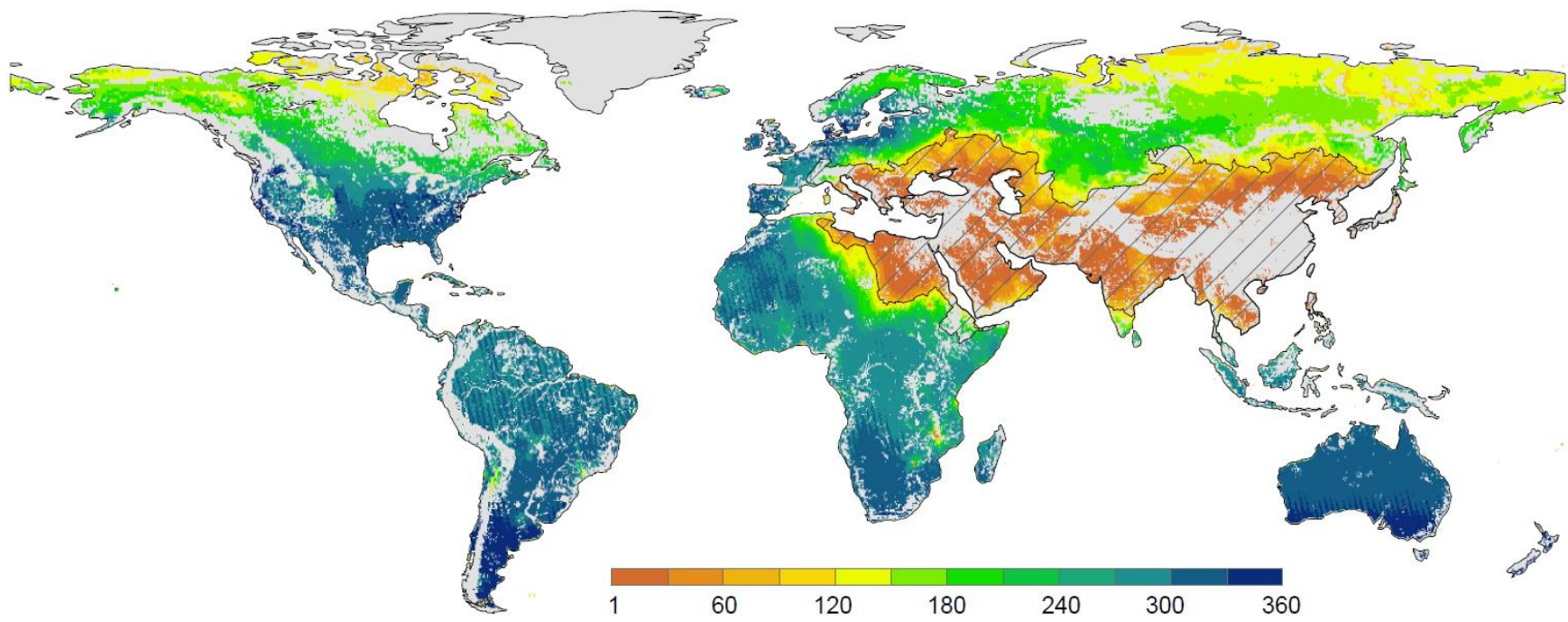

541 Extended Data Figure 2: Available number of SMOS VOD retrievals of the mean yearly daily time series (ascending 542 overpass).

543
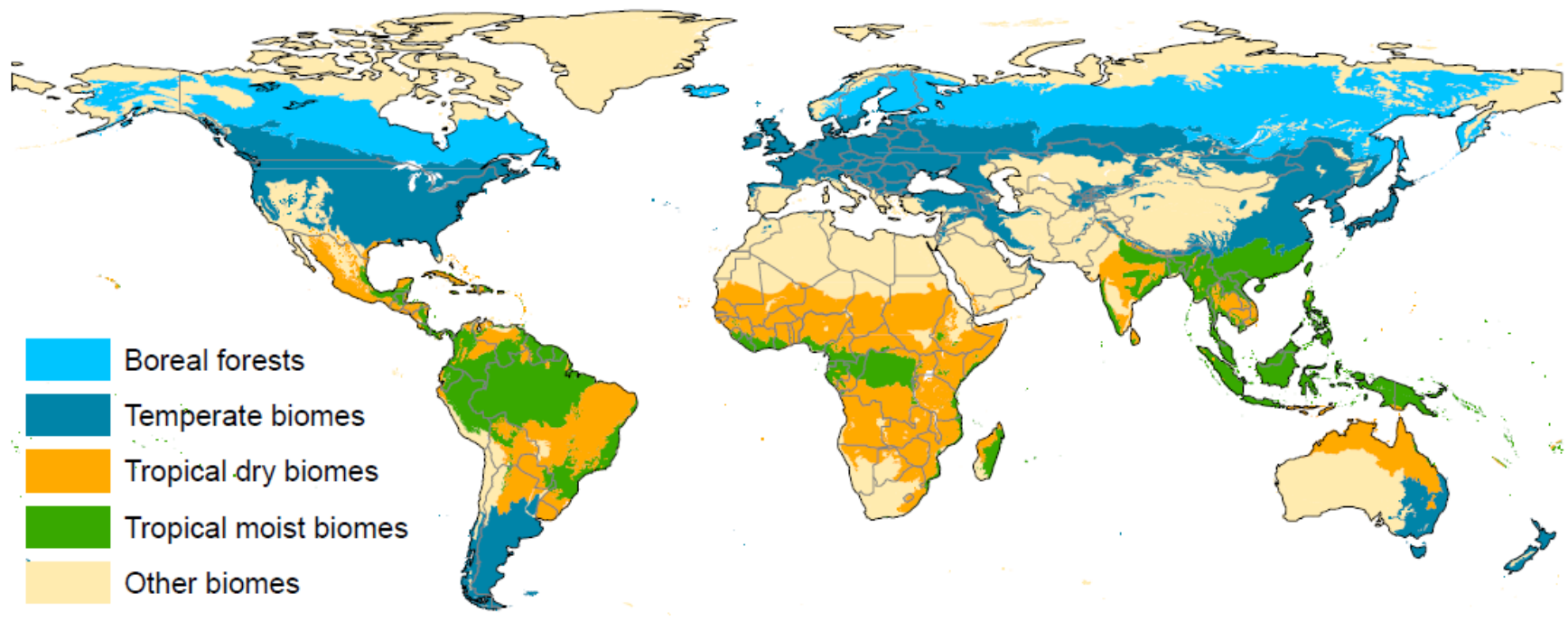

544 Extended Data Figure 3: Spatial extent of five merged regions. Modified from Olson, et al. ${ }^{26}$. The 'Other biomes' category contains deserts \& xeric shrublands, flooded grasslands and savannahs, mangroves, and was excluded from the analysis partly due to the higher uncertainties in these regions. 


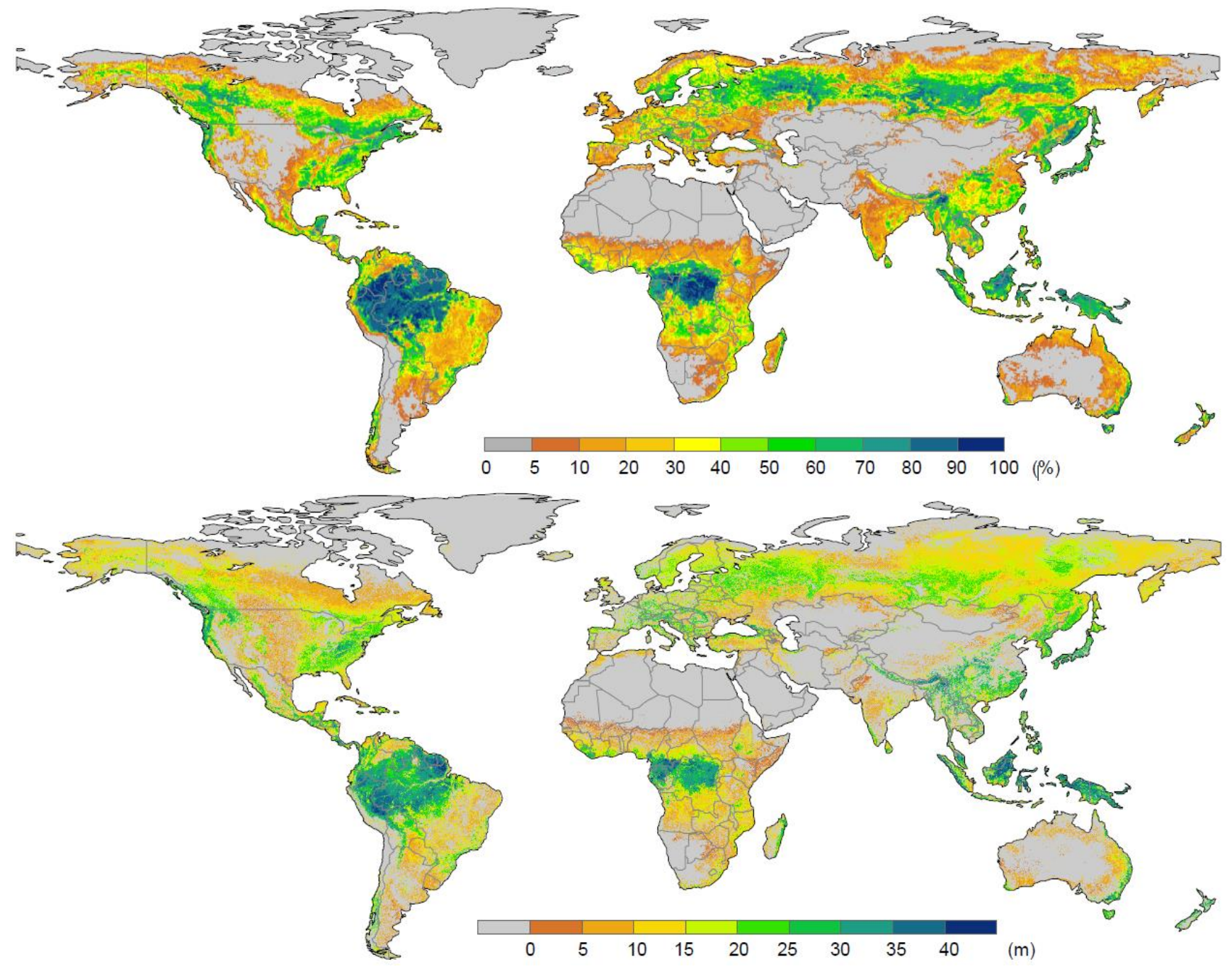

549 Extended Data Figure 4: Global tree cover fractions ${ }^{27}$ and tree height estimates ${ }^{58}$.

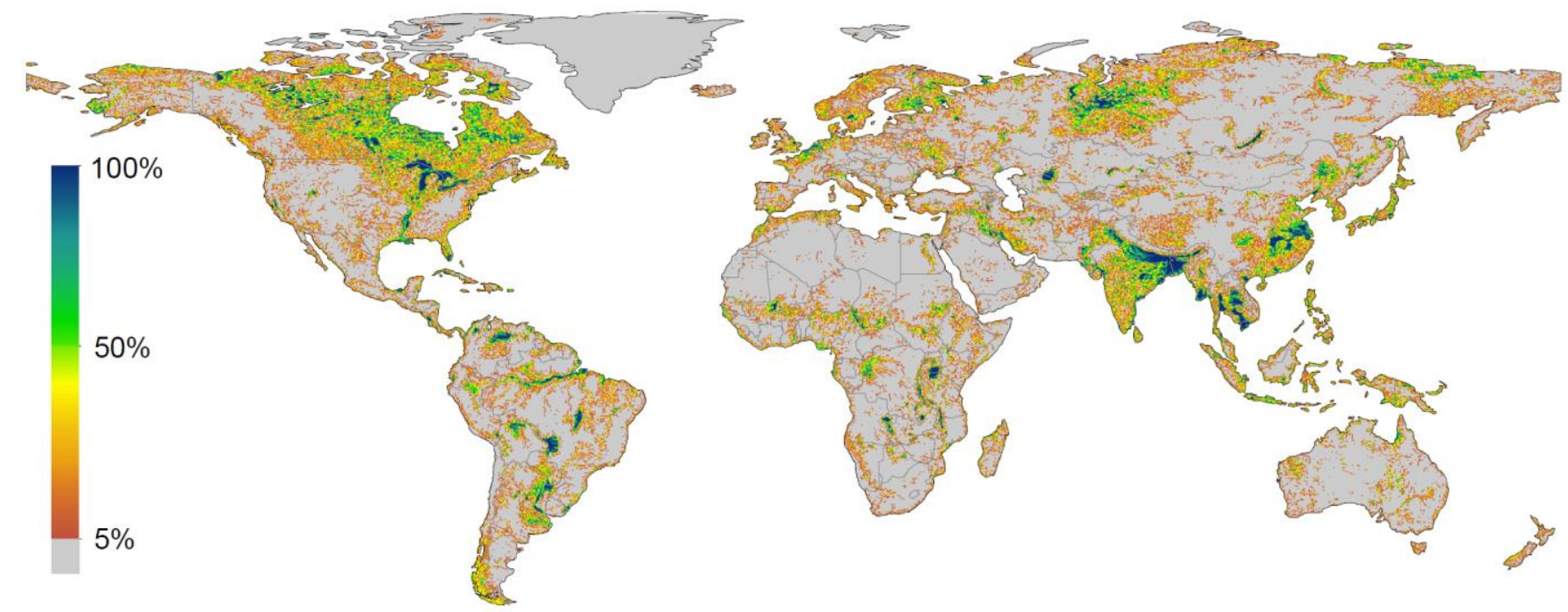

551 Extended Data Figure 5: Global inundation map ${ }^{28}$. 

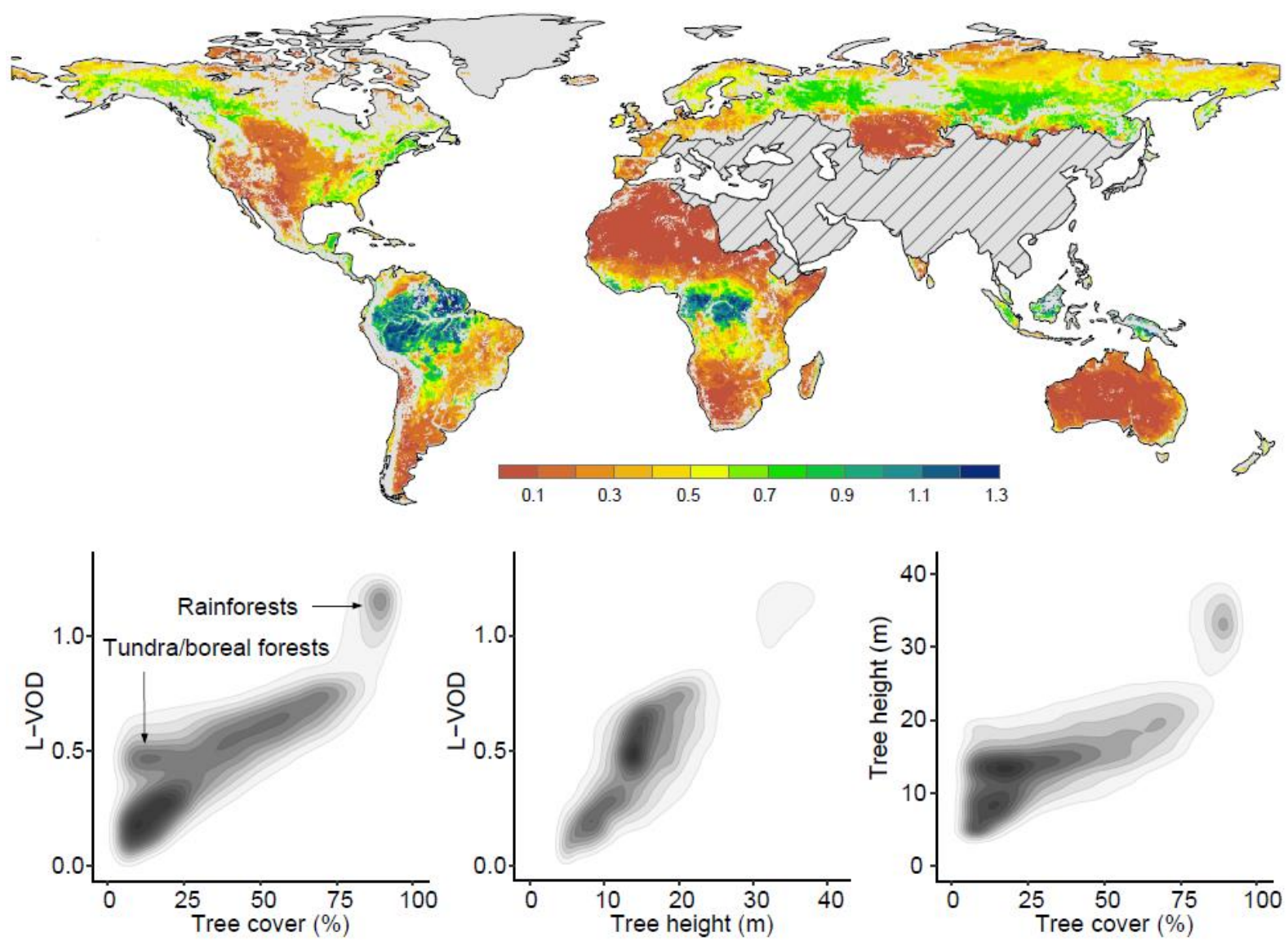

554 Extended Data Figure 6: Global variability in annual maximum L-VOD and the relationships with tree cover 555 fraction and tree height. 

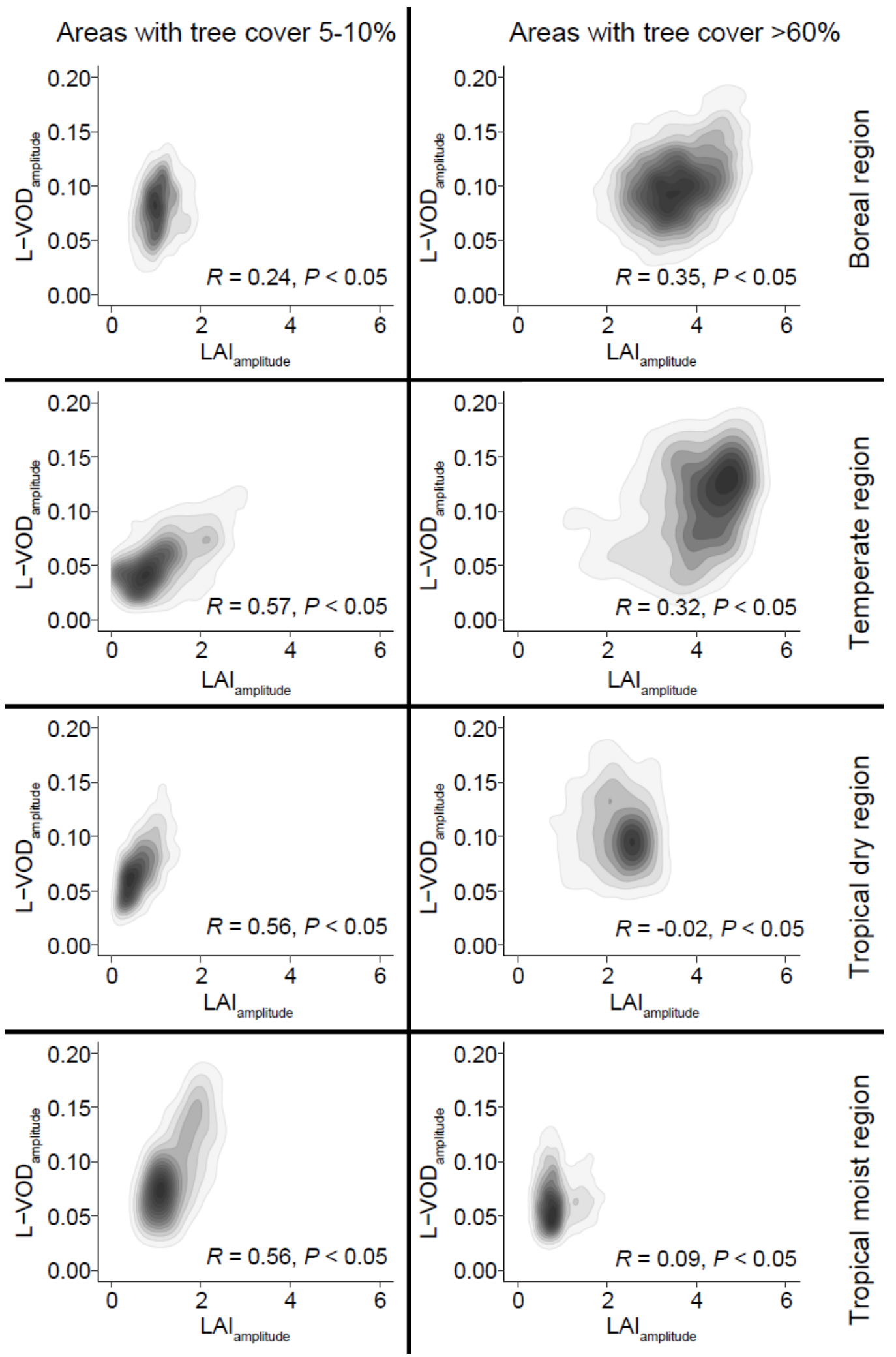

557 Extended Data Figure 7: Scatterplots between seasonal amplitudes of L-VOD and LAI, grouped by areas with tree covers 558 of $5-10 \%$ and $>60 \%$, respectively, within the boreal, temperate, tropical dry, and tropical moist regions. $R$ is the Pearson 559 correlation coefficient. 

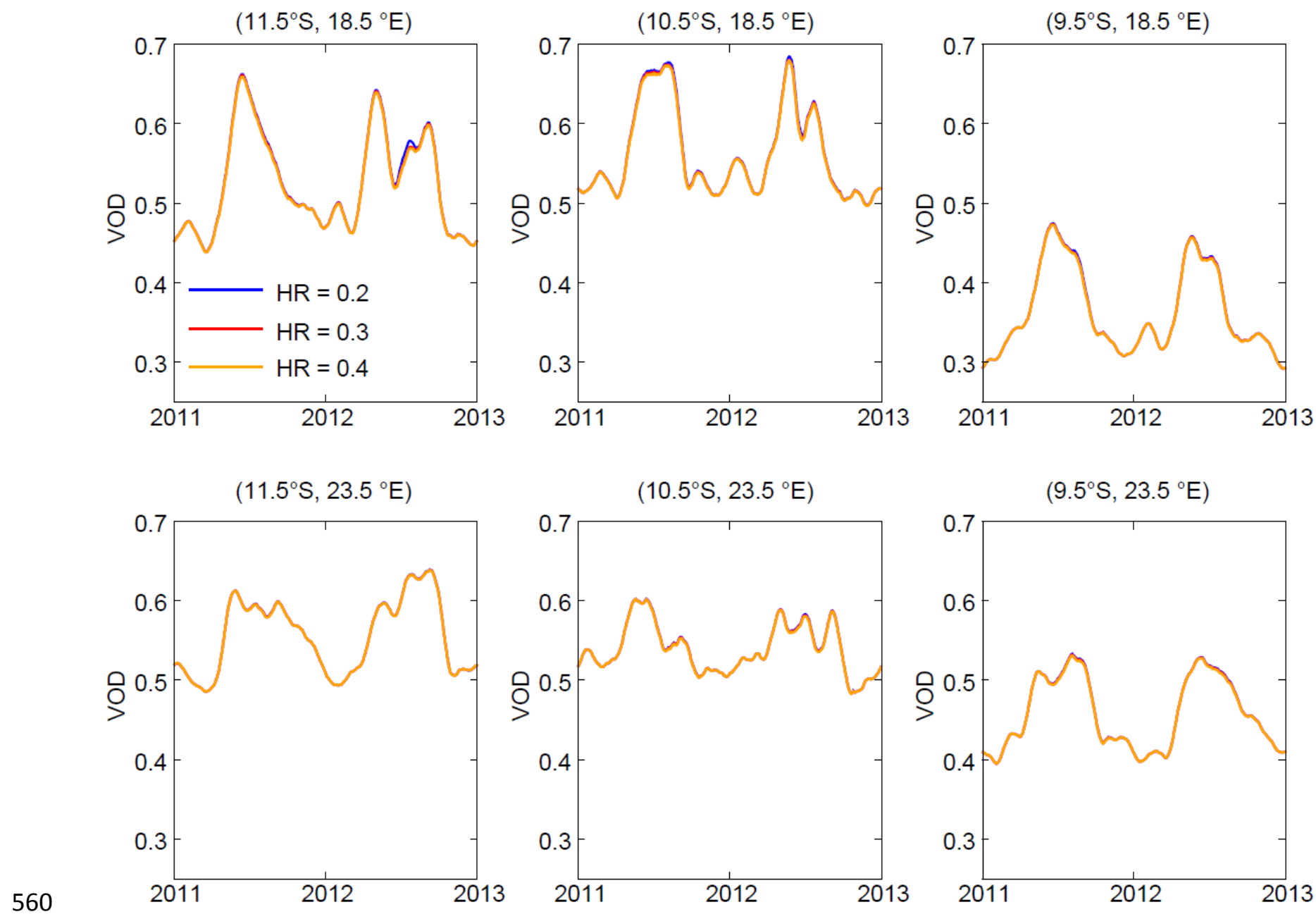

561 Extended Data Figure 8: Seasonal changes of L-VOD with soil surface roughness (HR) set to 0.2, 0.3 (used value in SMOS-

562 IC) and 0.4, respectively over six evenly distributed sites (one pixel for each) in the Miombo region (the upper left site is from 563 the same location as in Figure 5b). Note that curves with different HR settings almost totally overlap each other. 

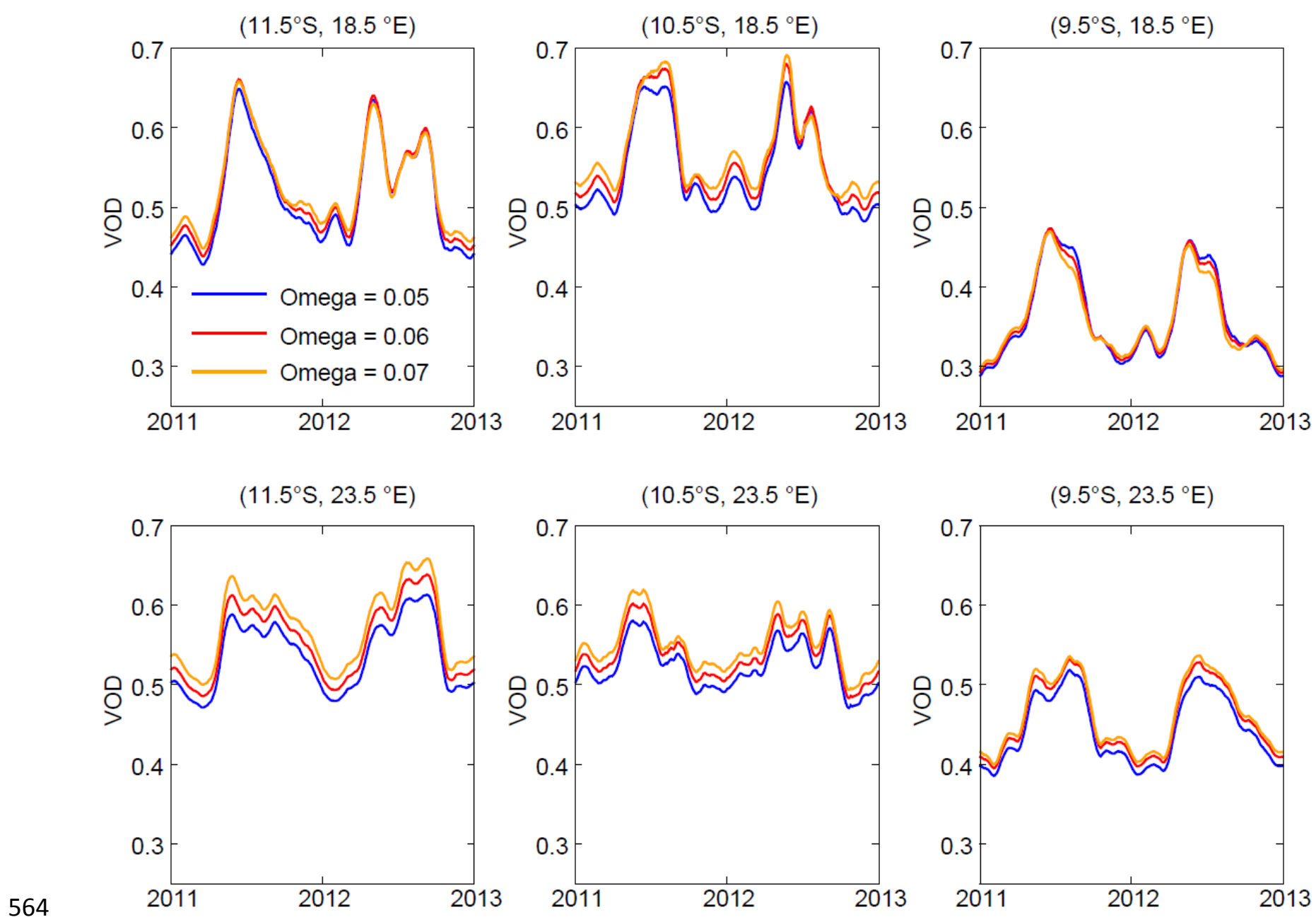

565 Extended Data Figure 9: Seasonal changes of L-VOD with effective scattering albedo (Omega) set to 0.05, 0.06 (used value

566 in SMOS-IC) and 0.07, respectively over six evenly distributed sites (one pixel for each) in the Miombo region (the upper left 567 site is from the same location as in Figure $5 b$ ). 

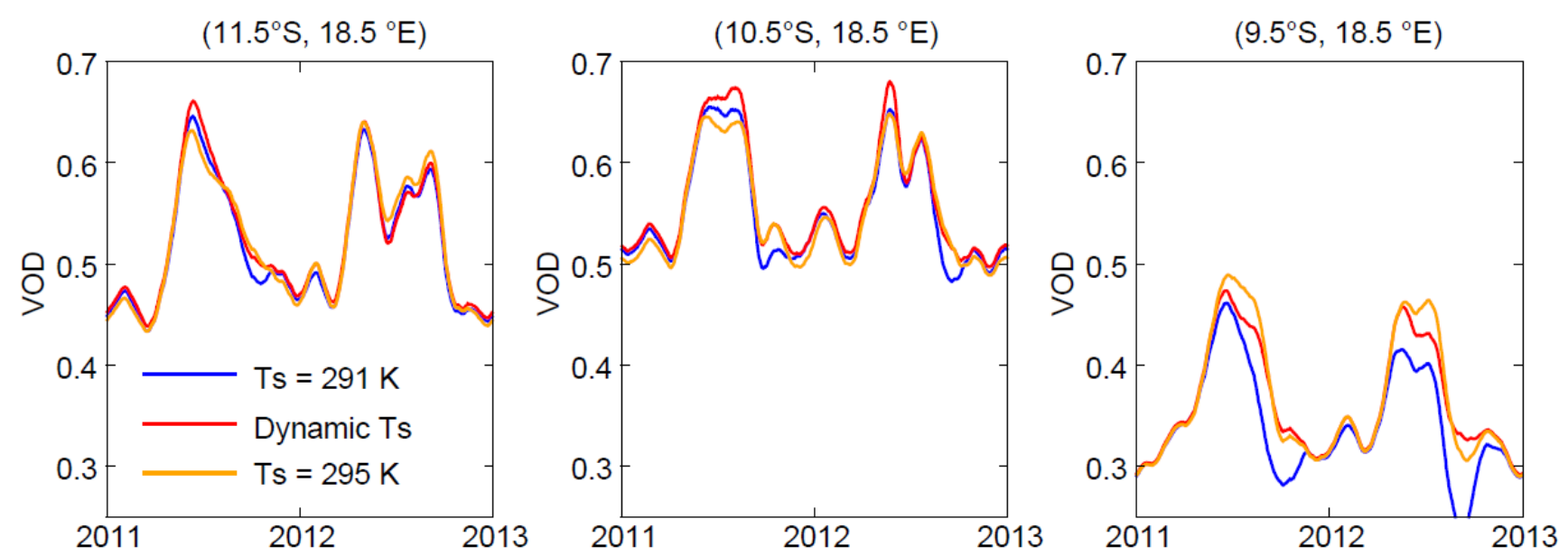

568

$\left(11.5^{\circ} \mathrm{S}, 23.5^{\circ} \mathrm{E}\right)$
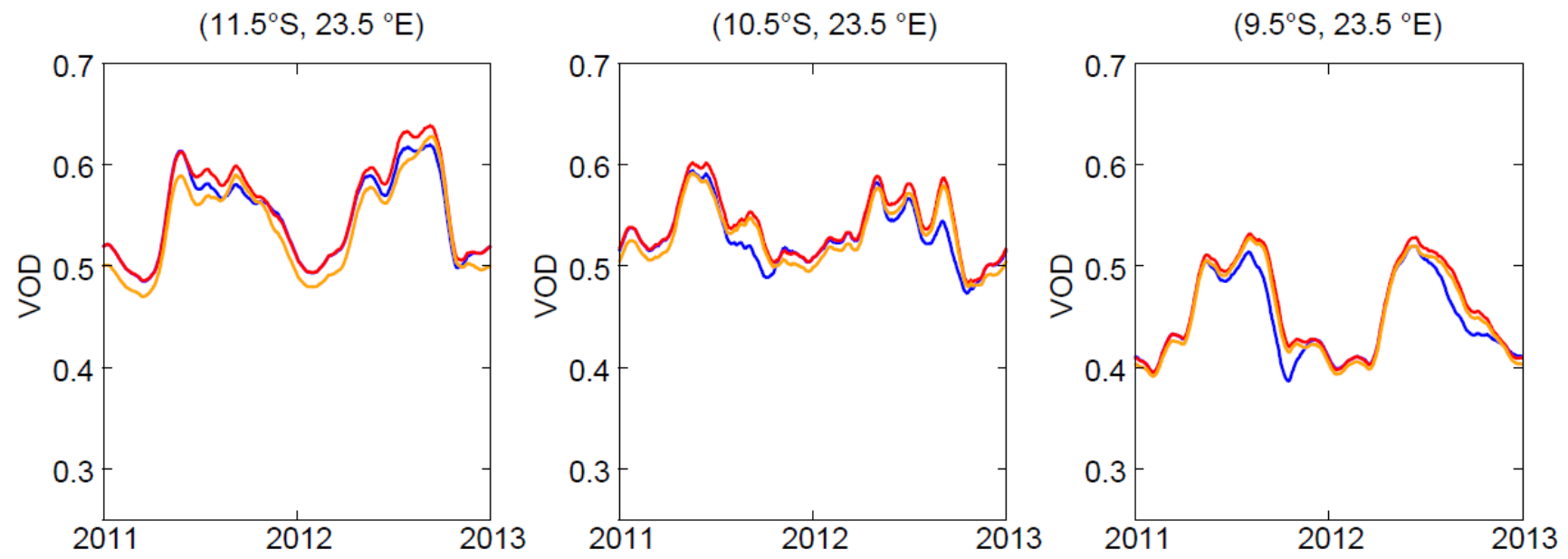

569 Extended Data Figure 10: Seasonal changes of L-VOD with effective temperature (Ts) set to constant values of $291 \mathrm{~K}$ and

$570295 \mathrm{~K}$ over the season, and to the dynamic ECMWF estimations (used in SMOS-IC), respectively over six evenly distributed

571 sites (one pixel for each) in the Miombo region (the upper left site is from the same location as in Figure 5b). 

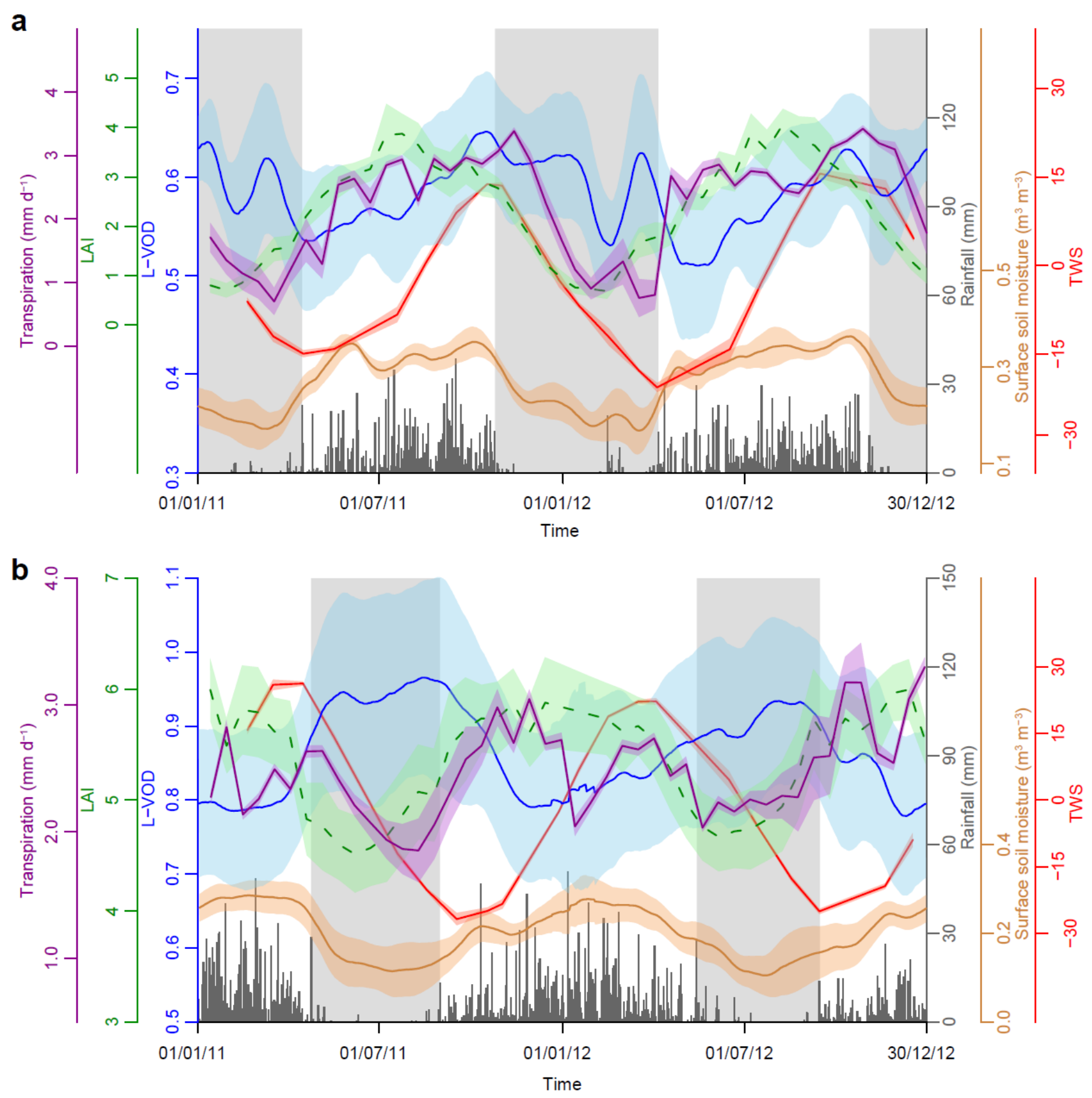

573 Extended Data Figure 11: a, An example time series (2011-2012) of plant water storage (L-VOD), terrestrial groundwater 574 storage anomaly (TWS), surface soil moisture, rainfall, transpiration, and canopy phenology (LAI) for northern African 575 woodlands located in south of Central African Republic centred at $5.5^{\circ} \mathrm{N}, 16.5^{\circ} \mathrm{E}$. The coloured shaded curves represent the 576 standard deviations ( $\mathrm{n}=16$ for all except TWS where $\mathrm{n}=3$ ). The grey shaded rectangles indicate the dry seasons. Tree cover $577=67 \%$. b, Same as for a, but for a location in the Brazilian Cerrado region centred at $11.5^{\circ} \mathrm{S}, 59.5^{\circ} \mathrm{W}$. Tree cover $=71 \%$. 